\title{
Strategizing Human Development for a Country in Transition from a Resource-Based to a Knowledge-Based Economy
}

\author{
Btool H. Mohamed ${ }^{1}$, Ibrahim Ari ${ }^{1, *(\mathbb{D})}$, Mohammed bin Saleh Al-Sada ${ }^{2}$ and Muammer Koç ${ }^{1, *(\mathbb{D})}$ \\ 1 Division of Sustainable Development, College of Science and Engineering, Hamad Bin Khalifa University, \\ Doha P.O. Box 34110, Qatar; btomohamed@hbku.edu.qa \\ 2 Mechanical Engineering, Branch Campus at Qatar, Texas A\&M University, Education City, \\ Doha P.O. Box 23874, Qatar; m.al-sada@qatar.tamu.edu \\ * $\quad$ Correspondence: authors: iari@hbku.edu.qa (I.A.); mkoc@hbku.edu.qa (M.K.)
}

check for updates

Citation: Mohamed, B.H.; Ari, I.; Al-Sada, M.b.S.; Koç, M. Strategizing Human Development for a Country in Transition from a Resource-Based to a Knowledge-Based Economy. Sustainability 2021, 13, 13750. https:/ / doi.org/10.3390/su132413750

Academic Editor: Jaya Krishnakumar

Received: 6 November 2021

Accepted: 7 December 2021

Published: 13 December 2021

Publisher's Note: MDPI stays neutral with regard to jurisdictional claims in published maps and institutional affiliations.

Copyright: (c) 2021 by the authors. Licensee MDPI, Basel, Switzerland. This article is an open access article distributed under the terms and conditions of the Creative Commons Attribution (CC BY) license (https:// creativecommons.org/licenses/by/ $4.0 /)$.

\begin{abstract}
Human development plays a profound role in achieving sustainable development, by utilizing the power of well-educated blue- and white-collar laborers, academics, politicians, and people from every layer of society and the economy. However, there is no single path for human development. Planning, designing, and implementing policies for human development require country-specific approaches, based on unique characteristics such as historical development trajectories, future goals, the commitment of leadership, culture, geography, and climate, to name a few. Such strategies become even further challenging for countries that aim to achieve radical transformations from resource-based to innovation-driven and knowledge-based economies, to achieve sustainable development. In this study, a conceptual model for a holistic human development strategy in line with sustainable economic development was first designed by employing design and systems thinking approaches. Second, under the guidance of this conceptual model, an integrated policy framework for Qatar is proposed to propel the quality and quantity of human capital to achieve economic diversification and, thus, sustainable development. Third, semi-structured interviews with experts and decision-makers in relevant fields were conducted to validate the feasibility and effectiveness of the proposed policy framework. As a proof-of-concept, the interview results validated-but were not limited to- the following outcomes. First, the proposed conceptual model has considerable potential to deliver robust, feasible, and effective policies from the initiation to the implementation of strategy development. Second, selectively recruiting highly skilled expatriate professionals under progressive residency policies provides incentives for them to become long-term residents. This would attract global human capital to complement the aim of economic diversification, a sustainable economy, and human development goals. Third, carefully designed university-industry-government partnerships and technical training programs will enable the development of appropriate innovation, professional, and business skills in the local population and facilitate economic diversification goals. Finally, empowering female entrepreneurs and investors will increase women's empowerment while accelerating economic diversification—and, thus, sustainable development.
\end{abstract}

Keywords: human development; human capacity; sustainability; economic diversification

\section{Introduction}

Human development has been recognized as the ultimate aim, and most determinant enabler, for a truly sustainable form of development that envisions delicately balanced economic, social, and environmental development. However, this was only recognized after a century of ignorance and the exploitation of humans as a source of labor or capitalor, at best, as capacity under the previous century's overarching dilemma of economic growth fueled by industrialization, capitalism, and hunger for consumption at the expense of social and environmental development [1,2].

Human capital theory (HCT) was officially formed in the 1960s by neoclassical economists, particularly Gary Becker and Theodore Shultz, although significant research 
had been carried out throughout the previous decades, even centuries [3,4] (please see the review of human capital theory between 1776 and 1960s in Sweetland (1996) [5]). In the industrialization era (19th and 20th centuries), the human as the labor was considered a factor of the production function along with land and capital, and thus an element of the economic capital according to the early human capital approach [6]. This view implies that human capital has an impact on economic development and growth [7]. Nevertheless, being a simple factor of production function induced a narrow understanding of the role of humans in economic development. In the context of growing automation and technological revolution accompanied by the views of capitalism in the 20th century, the perceived role of the human has advanced from a mere factor of production to an important source of human capacities and innovation, triggering economic development [8]. In this regard, Becker's (1964) seminal work demonstrated that the economic development of nations is connected to investment in individuals and illustrated the positive impacts and implications of educating and training people on the economy [9]. In other words, the HCT emphasizes the role of education in improving productivity and efficiency.

The rapid technological growth from the beginning of the 21st century brings awareness for sustainable development focusing on the environment, humans, and society. Besides, technological advances place humans at the center, and focal point of the approaches by development. In line with this, the HCT has evolved to enable technological advances by improving innovation capacity, R\&D participation, the education system, entrepreneurship, and gender equality [10]. In this regard, human development is essential for transitioning from rentier economies to first industrial and then knowledge-based economies, which leads to sustainable development [11]. In other words, the human's role shifted from a simple factor of the production function to the main goal and driver of economic development (see Figure 1).

\section{Human capital \\ - $19^{\text {th }}-20^{\text {th }}$ century \\ - Industrialization \\ - Capitalism \\ - Classical economic growth oriented \\ - Adverse impacts on society \& environment}

Human as a capital and factor of production

\section{〉 Human capacity $\quad \gg$ Human development}

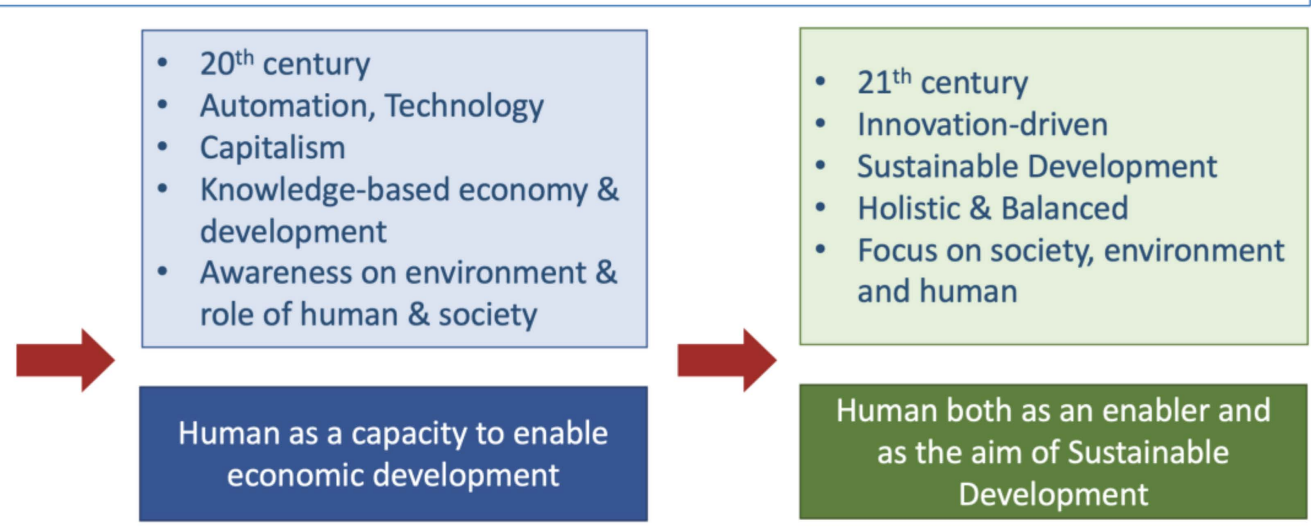

Figure 1. Human capital theories and models.

Many countries have recognized the importance of human capital theory for economic development, and some implemented substantially successful policy frameworks to enhance human development, such as South Korea and Singapore. South Korea was an economy that depended primarily upon agricultural produce and primitive manufacturing sectors producing textiles and bicycles [12]. As the first step in transitioning to a more advanced and diversified economy, heavy investments were made to upgrade its primary education standards, focusing on the quality and merit of K-12 education and other vocational training programs. South Korea has implemented a Development of Vocational Education and Training with a large variety of vocational high schools across a broad and diverse range of fields, aiming to raise the employment rate of high school graduates while encouraging them to pursue a college degree. Particularly since 2008, South Korea has been continuously expanding and adapting its policies in this regard, adding programs such as 
a specialized (vocational) high school, Meister High School (MHS), which emphasizes first employment, later college [13].

Another success story is Singapore. Its domestic market was small, but the government made Singapore export-oriented by utilizing its strategic location and increasing its industrial base. The objective was to attract overseas manufacturers seeking low-skill labor (e.g., garments, textiles, wood products) to gain expertise and decrease unemployment. In addition, Singapore has employed a "survival" mechanism, expanding basic education rapidly and providing targeted and robust education after primary school. As a result, Singaporean education shifted away from a one-size-fits-all strategy to a new approach that would offer numerous paths to decrease the student dropout rate as well as generate highly technical labor and skilled professionals who could meet the market's requirements that emphasized quality over quantity [14]. These examples and the literature indicate that implementing a successful human development strategy is one of the essential pillars of economic diversification. In this regard, Qatar recognizes the crucial role of human development in diversifying the economy by transitioning to first an industrial economy and then a knowledge-based economy.

A growing recognition of the value and necessity of human development for sustainable development has required all countries, including many in the Arabian Peninsula and the Gulf, to reconsider and rejuvenate their development frameworks, which are primarily dependent on the exploitation of natural resources, specifically oil/gas revenues $[15,16]$. Qatar has experienced rapid economic development due to its natural gas revenue and the effects of globalization over the past decade. Qatar has made significant strides in investing in selected non-oil sectors, with the hope of diversifying its economy. For example, Qatar has made significant investments in the financial sector at both the national and international levels. These well-calculated investments have started to yield dividends and improve Qatar's diversification profile compared to its neighboring states [17]. However, such diversification initiatives have yet to show their true and long-term impacts on Qatar's overall economic outlook. However, Qatar's economy remains heavily reliant on the revenue generated through the natural gas sector [18]. Therefore, numerous strategic international associations or alliances have been established with global multinational corporations over the last two decades. However, Qatar's goals require significant further efforts in this regard [19]. The Qatari government is currently pursuing the ongoing development of oil and natural gas [20] and boosting its banking sector [21]. The substantial revenues earned from this development trajectory should induce and accelerate a spillover effect through a broad range of diversified industries that are expected to initially shift Qatar's industrial economy away from hydrocarbon-based resources and then make it a global competitor among knowledge economies [18,22].

Qatar's leaders and policymakers have recognized this shortcoming and have taken actions to diversify the economy by prioritizing human capital enhancement as a critical factor of economic diversification. In this regard, the Ministry of Development Planning and Statistics (2015) has prepared a roadmap, Qatar National Vision (QNV) 2030, and defined human capital as the fourth pillar of sustainable development [23]. Moving toward 2030, Qatar's attention has been increasingly turning toward creating a fertile and innovative eco-system. Certain elements of this system already exist, while some are under construction and others have not yet been started. A significant amount of progress has been made over the past decade in education, health, and communication as well as information technologies, coastal development, and R\&D. Aspiring to achieve long-term social and economic sustainability, the Qatar Foundation (QF) and its subsidiaries within Education City, including the Qatar Academy, Academic Bridge Program, Hamad bin Khalifa University, the branch campuses of several US and UK universities, the Qatar National Research Fund, and the Qatar Science and Technology Park, are focusing heavily on human development by progressing specific education, higher education, and research initiatives [24]. Recently, Lusail University and Doha University of Science and Technology were approved for establishment [25]. Qatar has already initiated a promising development 
agenda and expended considerable effort over the last decade, which has resulted in the establishment of many institutions and initiatives. However, cultivating a society in which knowledge and innovation become widely diffused and provide a robust platform for wealth creation will take time [26]. Therefore, Qatar requires decision support systems and models to improve its development trajectory in human capital enhancement.

Due to Qatar's cultural, regional, and historical context, there has been social pressure to overlook females' participation in education, social activities, and the economy [27]. However, Qatari females are enthusiastic about overcoming such obstacles and participating in Qatar's development. For instance, her highness Sheikha Moza Bint Nasser Al-Thani has served as the chairperson of the QF and Education Above All Foundation and has been a staunch advocate of the United Nations (UN) Sustainable Development Goals (SDGs) [28]. She also supports female fashion designers around the Arab region as an honorary chairperson of Fashion Trust Arabia and has founded the Qatar Social Work Organization [29]. Furthermore, the number of females pursuing higher education in universities is significantly higher than the number of males [30]. Nearly $75 \%$ of Qatari admissions in QF universities were female, with a total of 1078 admissions compared to only 371 males in 2020 [31]. Qatari women have experienced success stories over the past decade in the business field as well as in education. However, there are still no formal policies for incorporating women into each layer of the country's development, while social barriers to female participation continue to exist. Since entrepreneurship serves as a useful example of providing opportunities for women, the government should commit itself to investing in ideas and opportunities for female entrepreneurs. These could provide women with new and flexible options to select based on their skills and abilities while also enabling them to contribute to Qatar's economic development. Therefore, there is a need for a policy framework to increase women's empowerment by incorporating females into the economy.

There is still much room for improvement in human capital and female empowerment in Qatar to achieve economic diversification and sustainable development. In this regard, the present study proposes an integrated policy framework that involved synchronizing all entities in the framework with interaction relations. This was accomplished by first developing a holistic conceptual model from the initial to the final stage of policy development, while utilizing a design and systems-thinking approach. We then employed this conceptual model for the proposed policy framework in Qatar.

\section{Literature Review}

The literature review begins with a detailed review of research on economic diversification and continues with a section related to human capital enhancement, which includes subsections on education, university-industry partnership, and attracting global human capital as important components in the toolset for human capital enhancement. The literature review also outlines female empowerment aimed at promoting female entrepreneurship.

\subsection{Economic Diversification}

The challenges for a transition to sustainability have been acknowledged by the state of Qatar, which recently laid out grand policy strategies under the umbrella of Qatar National Vision 2030 (QNV 2030) [32]. With an emphasis on a knowledge-based transition, the QNV 2030 program involves the reconciliation of competitive policy priorities to gain knowledge and achieve sustainable development. Furthermore, it addresses the population imbalance between local citizens and expatriates as well as the country's aspirations to maintain similar levels of revenue and GDP per capita levels in the coming decades. The Qatari human development plan aims to prepare its citizens for knowledge-intensive industries and ensure the steadfast replacement of its low-skilled expatriate workforce with well-trained foreigners. The challenge of how the Qatari state is to achieve the transition to a knowledge-based economy merits further research because a failure to achieve this transition will inevitably have long-term ramifications for Qatari development prospects. 
Consequently, QNV 2030 highlights human capital development as a pathway to move from a hydrocarbon-based to a knowledge-driven economy.

Developing human capital is crucial in the contemporary setup of modern economies [8]. Excessive reliance on primary production keeps labor from acquiring more lucrative skills and careers, while also making economies less sustainable [33]. Contemporary economics is mixed and requires manufacturing and trade. Countries worldwide are realizing that their resource-based incomes are running dry, and an emphasis is being placed on fostering new approaches toward economic development [34]. For example, Norway obtained $25 \%$ of its total revenue from oil-related economic activities. However, the value of its oil-based industry has fallen by $\$ 50$ billion [35]. Norway is now relying on healthcareand space-related initiatives [36]. The Norwegian government is also supporting start-ups. While the government is still reluctant to restructure its tax and regulatory systems to make it friendlier for entrepreneurial start-ups, the need for a change in the country's economic system and factors of reliance are being recognized. In this context, while Qatar has a significant abundance of hydrocarbon resources, it is facing a dire shortage of water, soil, local population, and other raw materials to sustain growth in this direction [37]. As a result, it is crucial that Qatar develops its human capital and maximizes efficiency in using its resources. Thus, the country must diversify its approach to developing institutions for the education, healthcare, and social welfare of its population to elevate its social and economic status. Moreover, since there is also a pressing need for the country to reduce its reliance on global human capital, the government must invest outside the scope of its resource-based industries to develop infrastructure that can qualify its population for economic activities.

The contemporary economy is also increasingly dependent on the inclusion of female entrepreneurs, decision-makers, and participants [38]. Notably, the causality between women's empowerment and diversification has been validated in the literature [39]. Since it is established that economies need to be diverse, the crucial shortcoming of excluding women from economic activities is that the variety of goods and services produced in a country decreases significantly with limited female participation [40]. It also decreases the amount of potential human capital available in an economy. Ultimately, lower female participation in the labor force is resulting in the underutilization of the country's potential human capital. Equal access to state tools for human development, such as education, healthcare, and skill development opportunities, is essential in this regard. Empirical evidence suggests that inequality in the aforementioned sectors, as well as in labor force participation, are factors that limit growth [41]. With equal opportunities granted in these spheres, a country's economic approach can diversify. The first step toward this would be promoting opportunities for women within the economic scope of the country. For countries whose economies are suffering from the recent decrease in commodity prices, it is especially important that they diversify their economic approach.

\subsection{Human Capital Enhancement}

This subsection is focused on human capital enhancement. Although human capital has many components, this study only focuses on education, university-industry partnership, and attracting high-level global human capital to serve as competition and a benchmark for local human capital.

\subsubsection{Education}

This subsection aims to provide a comprehensive review of recent developments in the Qatari education sector.

Significant investments and focus have been placed in Qatar's education field. Since 2002, comprehensive institutional reform has strengthened the education system [42]. This investment process began with the reform of the K-12 education system. In 2003, the Supreme Education Council was established to oversee the deployment of an independent school system, offering more choices and greater accountability. Additionally, the Qatari 
leadership has assigned a significant share of its GDP to education over the past seven years. The government has generally invested in infrastructure enhancements to improve the quality and quantity of educational institutions operating at the primary, secondary, and tertiary levels.

The Qatari educational system has been subject to significant reorganization and improvement over the past decade. However, benchmark indicators still show that the academic achievement of Qatari students is always behind that of their counterparts in the developed world [43]. According to research commissioned by the OECD's program for international student assessment, Qatar was ranked 61 out of 65 studied countries in terms of educational quality in 2018. Only students from Panama, Peru, Azerbaijan, and Kirgizstan scored lower than their Qatari counterparts [44].

Such results seem to suggest that Qatar's economic and educational reforms have not reached the level of change that the country has aimed for and, effectively, smoothed out the transition to a knowledge-based economy in recent years. Thus, there is a need for systemic improvements within the educational sector to ensure that the best practices for developing human potential are enacted. The following points are salient factors and shortcomings in Qatar's educational case that will fall under the policy proposals of this study.

Qatari females outnumber their male counterparts in tertiary education by a factor of three to one; however, despite this higher education dominance, they are unable to gain employment and key positions in the male-dominated oil or construction industries. Moreover, they typically settle for less demanding urban jobs due to socio-cultural constraints. Consequently, there is a lack of equal opportunities and plans for female advancement, especially in terms of entrepreneurship, which is one of the required pillars for transforming a knowledge economy [45].

Qatar's expatriate population is predominantly male, with most individuals coming from emerging or relatively developing countries and humble educational backgrounds. These workers are mostly employed on contractual terms and serve as an unskilled or semi-skilled labor force to complete infrastructure projects associated with the upcoming FIFA World Cup 2022 [46].

There is an absence of innovation and entrepreneurship training as well as experimentation opportunities for students and teachers at the K-12 level [47].

Overall, the Qatari population is not inclined toward advanced technological education and vocational training or knowledge economy-related majors. Thus, Qatar's current industrial outlook is devoid of any advanced technological industry (IT/manufacturing) and cannot accommodate such qualifications [48].

\subsubsection{University-Industry Partnership}

This subsection focuses on partnerships between academic and business organizations, which represent a natural extension of education.

Having completed the basic infrastructure and services for health, education, transportation, and communication, Qatar is now at the junction of focusing on and improving the quality and efficiency of its institutions for alignment with knowledge-based sustainable development. Thus, it needs to shift and upgrade its education system to excel in high quality and competitive achievements in skills, talent, and capacity building (e.g., STEM, vocational and technical education, and training), while integrating its higher education, science, technology, research, development, and innovation efforts into strong and progressive partnerships with its core oil/gas industry, as well as the industry and economic sectors noted in the QNV 2030 goals.

Qatar must also pay close attention to developing tailored and progressive policies, programs, and mechanisms to overcome the following university-industrial shortcomings:

1. Lack of precise requirements from industry regarding what majors are needed in terms of either quality or quantity. The broken chain between educational supply and industrial demand is negatively influencing many aspects, including student motiva- 
tion and financial impacts. In short, universities are supplying random solutions to unspecified problems [49].

2. The absence of a collaborative environment between educational institutions and industry that aims to create an innovative field of research based on the partnership of key industry actors while also supporting local industry-driven research, development, and innovation (RDI) [50].

3. A shortage of partnership strategies between industry, universities, and K-12 institutes-especially in terms of development in the areas of technology, research, and innovation [51].

\subsubsection{Attracting Global Human Capital}

The most prominent outcome of importing human capital from all over the world is diversifying the local market with learning opportunities and skillsets that were not previously available [52]. Foreign human resources elevate the standards of local human capital by increasing competition [53]. Thus, the local environment is introduced to standards for procedures, efficient operational strategies, and contemporary practices and requirements in skill-based segments of the economy. In essence, this diversification leads to increased challenges for local human capital, which can exponentially expand its potential, if overcome [54]. The induction of global capital to create secondary effects on local capital is similar to the example of corporates recruiting high-level human capital to increase the performance standards and work methodologies of low-level capital [55]. On a national level, this example can translate directly. However, some challenges come with global capital recruitment. For example, countries may fail to secure residency or citizenship for this recruited capital, which will lead to short-term inductions that may have little effect on the stated purposes. Similarly, while a state may expect positive outcomes from this process, the reliance on global human capital can also have an undermining effect on local human capital, especially if it is favoring the foreign segment of human capital in proportion, gratifications, and opportunities. Notably, Qatar must pay close attention to naturalizing highly skilled residence and Qatarization in the proposed policy.

\subsection{Women's Empowerment: Female Entrepreneurship}

This section provides a discussion on the need for women's empowerment in the entrepreneurship field as a pathway toward the effective diversification of the Qatari economy.

Existing research has noted that the scope of female entrepreneurship is very weak in Qatar and other GCC countries [56]. The World Economic Forum reported that Qatar ranked 132nd out of 153 countries in facilitating women's economic participation and opportunity [57]. However, women have the provision of equal and non-discriminated access to human development functions of education and skill development. In this regard, equal human development but unequal economic participation implies that cultural and social barriers prevent women from easily accessing economic and business activities that are crucial for the diversity of a country's economy [58]. Empirical studies have also shown that women in Qatar do not have equal opportunities in terms of economic participation [59]. This situation is represented by the unemployment rates of females, specifically female millennials, who are struggling to find employment in the country. The principal requirement behind the urgency Qatar must observe in including women in its entrepreneurial structure is the weak gender development stereotypes associated with Qatar and the region in general [60]. Based on these stereotypes, the role of families in upscaling the human development of society is largely absent. Within the context of the current paradigm shift that Qatar is experiencing, while shifting from a resourcebased economy to one that necessitates high human development, it is crucial for the entrepreneurial culture to feature more female leaders and investors. While this would require an extensive restructuring of the role and outlook of families as well as economic 
stakeholders, it is necessary in order to fulfill the policy outcomes and follow the plans that Qatar has laid out for human capital development.

\section{Methodology}

This study utilized a design thinking process consisting of five main components: discovery, interpretation, ideation, experimentation, and evolution [61]. Figure 2 illustrates the design thinking approach followed in this study. In the first stage, we examined various obstacles pertaining to Qatar's economic diversification - and thus sustainable developmentthrough brainstorming meetings with the various field experts and by reviewing the literature. Then, we formulated a problem statement focusing on Qatar's relatively low educational success and female empowerment for economic diversification in the context of moving toward sustainable development. This perspective demonstrates the serious untold shortcomings that need to be recognized and addressed with appropriate, integrative, and long-term policies that synchronize all stakeholders. Therefore, in the interpretation phase, we developed a conceptual model based on a comprehensive literature review for a policymaking framework in a well-defined systematic mechanism, by employing the systems thinking approach. This conceptual model incorporates stakeholders, decision-makers, policy proposals and validation, financial and legal assessments, risk and impact analysis, implementation, and monitoring stages. In the third phase, we proposed six policies and validated them by conducting semi-structured interviews with the associated field experts. The last two phases - experimentation and evolution - will require implementing the proposed policies and evaluating them in a real-world environment. Policy implementation is a delicate process that involves lengthy and complex procedures (including governmental permissions) because it has profound, long-term influences on society and the economy. Therefore, we provided a roadmap for implementation along with a brief risk and impact analysis. We then set future work for a pilot study and the evolution phase.

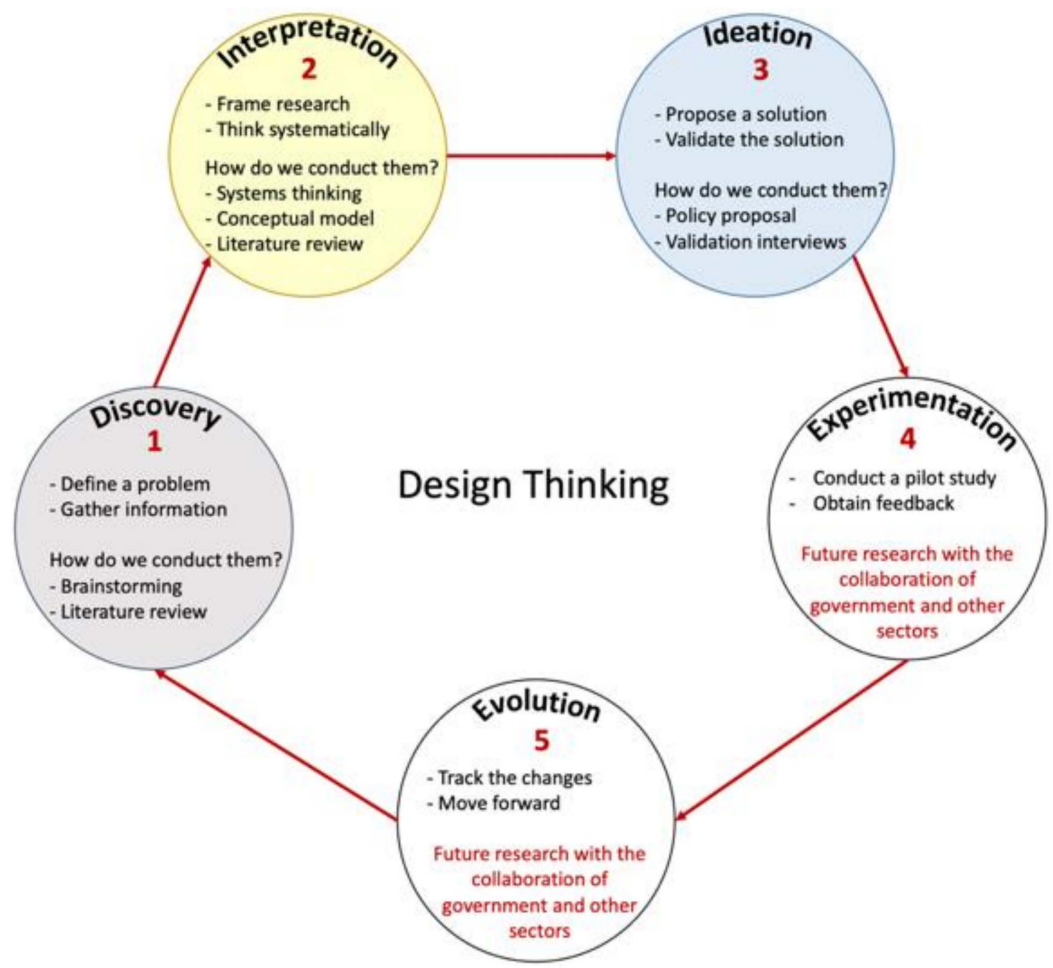

Figure 2. The design thinking approach used for this study.

\subsection{Systems Thinking: Conceptual Model Development}

The conceptual model utilizes the systems thinking approach and represents a critical component of the research methodology. This type of research is defined as an "inter- 
mediate artifact for system construction" [62]. A conceptual model offers a schematic representation of the theory or system falling under the focus of the research, which is enhanced by the inclusion of the key concepts laying the basis of the study [63]. According to Meredith (1993), the definition of a concept as "a bundle of meanings or characteristics associated with certain events, objects, or conditions" emphasizes the importance of conceptual clarity and modeling in the research process [63]. Due to the representation of essential concepts interlinked with their relationships, interplays, and building blocks, the conceptual model presents a valuable methodological research tool providing a clear understanding of the systems under examination. Conceptual frameworks play a crucial role in the theory development process, which is based on defining, explaining, testing, and establishing the components of systems and theories [63].

Conceptual models can be divided into three general classes: conceptual induction, conceptual deduction, and conceptual systems. Conceptual induction aims to provide a detailed understanding of the mechanisms underlying a system based on inferences about the reality, whereas conceptual deduction is focused on the ramifications or offers predictions about the system and its development [63]. In this study, we employed conceptual systems, which represent the interplay and relationships between the separate elements of the system being investigated [63]. In a broader sense, Meredith (1993) stresses the extensive power of conceptual frameworks to present or describe processes, systems, and objects [63]. However, their ability to provide an evidence-based explanation of the focal research phenomena remains limited.

The literature also provides controversial critiques regarding the applicability of conceptual models. For instance, Robinson (2015) noted that there is a risk of providing a distorted view of the system under study in the case of a failure to develop a sufficiently transparent and comprehensive conceptual model [64]. However, Lüdeke-Freund (2020) emphasized that conceptual models are indispensable for moving from definitions and theories to explanations and applications, by integrating available knowledge through systems thinking [65]. Despite this, they also recognized the validation problem of the conceptual frameworks. Therefore, this study proposed a second layer on top of the conceptual model for enhancing human capital development and female empowerment, which involved validating the proposed concepts by conducting semi-structured interviews with the associated field experts.

\subsection{Validation: Semi-Structured Interviews}

This study aims to validate and improve the policies proposed in the conceptual model for improving human development and female empowerment. Across scientific fields, validation refers to the practice of establishing confidence in a framework, model, or procedure by determining its utility with respect to an intended use [66]. Empirical research with experts, such as focus groups, surveys, and interviews, is frequently used for framework validation [67], whereas statistical tests may be used for other validation tasks (i.e., questionnaire validation) [68].

In this research, the semi-structured interview method was selected to validate the proposed conceptual model and provide recommendations. One of the reasons for selecting interviews was the fact that this data collection method is usually associated with a higher response rate when compared to other methods (e.g., questionnaires), which is favorable for eliminating potential sources of bias [69]. Furthermore, the interviewer can supply individual interviewees that provide the necessary information when they need it, which is not possible with focus groups or self-completion questionnaires [70]. Furthermore, interviews tend to be directed more toward reducing the potential confusion of respondents, thereby improving the quality of the obtained data [70]. Interviews also allow the framework validation process to benefit from the rich and fine-grained qualitative data gathered from knowledgeable decision-makers and policymakers, which is ideal for adding credibility to the validation [71]. 


\subsubsection{Sampling and Participant Selection}

This study considered the appropriate sample based on the field of expertise. Therefore, the research sample consisted of professionals with expertise in associated policy proposals. In other words, the sample comprised decision- and policymakers in the education system for human capital and social institutions for female empowerment in both the private and public sectors. Since this segment of the population is difficult to locate, a snowball sampling strategy was adopted. In this strategy, research participants were asked to refer other potential participants who satisfy the inclusion criteria [72]. Selections were made based on purposive sampling and participants' willingness to participate.

The principle of theoretical saturation was used to determine the required sample size. The recruitment of respondents was discontinued when no new data, ideas, or constructs were yielded by further data collection [73]. Under these conditions, the sufficient number of respondents was determined as 15, from all sectors and both genders. Table 1 presents the demographic composition of the interviewees.

Table 1. Demographic composition of the sample.

\begin{tabular}{|c|c|c|c|c|c|c|}
\hline Respondent & Gender & Age & Qatari & Profession & Education & $\begin{array}{l}\text { Current } \\
\text { Sector }\end{array}$ \\
\hline IR1 & $\mathrm{F}$ & $30 \mathrm{~s}$ & YES & Engineer & Master & Private \\
\hline IR2 & M & $50 \mathrm{~s}$ & YES & $\begin{array}{l}\text { University } \\
\text { President }\end{array}$ & Ph.D. & Education \\
\hline IR3 & $\mathrm{F}$ & $40 \mathrm{~s}$ & YES & Director & Ph.D. & $\begin{array}{c}\text { Education and } \\
\text { Research }\end{array}$ \\
\hline IR4 & M & $40 \mathrm{~s}$ & YES & $\mathrm{CEO}$ & Ph.D. & Education \\
\hline IR5 & $\mathrm{F}$ & $50 \mathrm{~s}$ & YES & $\begin{array}{c}\text { Assistant } \\
\text { Undersecretary }\end{array}$ & Master & Education \\
\hline IR6 & $\mathrm{F}$ & $30 \mathrm{~s}$ & $\mathrm{NO}$ & Manager & Master & Private \\
\hline IR7 & $\mathrm{M}$ & $40 \mathrm{~s}$ & YES & Director & Ph.D. & Private \\
\hline IR8 & $\mathrm{F}$ & $50 \mathrm{~s}$ & YES & CEO & Master & Education \\
\hline IR9 & $\mathrm{M}$ & $40 \mathrm{~s}$ & $\mathrm{NO}$ & Manager & Ph.D. & Military \\
\hline IR10 & M & $30 \mathrm{~s}$ & YES & $\begin{array}{c}\text { Planning and } \\
\text { Quality } \\
\text { Manager }\end{array}$ & Bachelor & Public \\
\hline IR11 & M & $50 \mathrm{~s}$ & NO & $\begin{array}{l}\text { Quality } \\
\text { Manager }\end{array}$ & Ph.D. & Public \\
\hline IR12 & M & $50 \mathrm{~s}$ & NO & $\begin{array}{l}\text { Economic } \\
\text { consultant }\end{array}$ & Ph.D. & Public \\
\hline IR13 & $\mathrm{F}$ & $30 \mathrm{~s}$ & YES & Engineer & Ph.D. & Private \\
\hline IR14 & M & $30 \mathrm{~s}$ & YES & $\begin{array}{l}\text { Quality and } \\
\text { Planning }\end{array}$ & Master & Public \\
\hline IR15 & $\mathrm{M}$ & $50 \mathrm{~s}$ & $\mathrm{NO}$ & Military Rank & Ph.D. & Military \\
\hline
\end{tabular}

The interview guide was sent to the participants via emails that entailed a fourslide presentation summarizing the proposed policies in the conceptual model with a brief introduction to the study. This presentation was also presented in 5 to $7 \mathrm{~min}$ at the beginning of each interview, to enable interviewees to clearly understand the conceptual model and framework, before providing their comments and critiques. The interviews were conducted via video meetings through Zoom, which is a well-known online meeting and conference software. Consent letters were provided to interviewees to obtain their approval for participation in the study. Additionally, the interviews were conducted in the English language. Each interview lasted between 30 and $45 \mathrm{~min}$. The responses of 
the participants were recorded in a "data notebook" (an interview sheet) to maintain participants' confidentiality. The interview sheet consisted of a table with the columns of agreement level scale (low, medium, high) for validation and the validation criteria. The respondents were asked about their agreement level for the proposed policies and their suggestions for improving the policy framework.

\subsubsection{Data Analysis}

The transcribed qualitative primary data gathered through the semi-structured interviews were analyzed using the qualitative data analysis framework proposed by Miles and Huberman (1994) [74]. These authors suggest a data analysis process starting with data collection and followed by three analytical stages: data reduction, data display and conclusion drawing, and validation. This analytical framework was selected for the present research due to the clear and structured approach provided for the analysis of collected data, which allows for relatively simple analysis for the interpretation of the research findings [75]. Furthermore, this data analysis (including the three main components) enhances the quality of the conclusions drawn from the qualitative research [76].

\section{Data Reduction}

Data reduction is the process of condensing, summarizing, and classifying identified items in the information pool to eliminate any data that do not serve the purpose of answering the research questions [75,77]. To implement data reduction, all of the transcripts were read more than once to clearly understand the context. Significant ideas that could be identified were selected as important opinions. Next, the researcher categorized the given opinions, relevant phrases, words, and sentences of the validation criteria. These were gathered from the different responses and highlighted based on their relevance. The validation criteria for the framework and recommendations varied based on the interviewees' responses in the interviews, where each proposed different measures based on their sector of experience. However, the general classes of the measures (i.e., economic, behavioral, social impact, and strategic impact) were addressed and verified.

\section{Data Display}

Data display refers to the process of displaying data visually using various methods (e.g., graphs, charts, and diagrams). Qualitative data can be displayed using bar and pie charts. A series of flow charts can also provide substantial evidence regarding whether or not to validate policy proposals, by determining the critical points in a path and the major decision points. Thereafter, the data is ready for drawing conclusions [74]. After capturing the impact of each policy, a clearer view of involved parties was defined (i.e., planners, implementers, evaluators).

\subsubsection{Validity}

The present study involved subject matter experts for semi-structured interviews. In this regard, the supervisory committee members reviewed the interview sheet in terms of its language, wording, and relevance. Thereafter, we edited the interview sheet according to suggestions on interview flow and captured the agreement level for the suggested improvements. Following the initial review and revision, we performed a pilot study for the semi-structured interviews with two of the participants before conducting the actual interview. This approach facilitates the detection of possible flaws that may require adjustment in the interview at an early stage, which adds value and credibility to the research [78]. The participants in the pilot interview did not report any significant difficulties in understanding the requirements, except that some were unable to comment on certain policies that are not directly related to their field or profession. Therefore, in the actual interviews, more effort was devoted to explaining and relating to interviewees' professions. 


\section{Results and Discussion}

\subsection{The Conceptual Model: Human Capital Enhancement and Female Empowerment for Economic} Diversification

The purpose of the conceptual model presented here is to provide a roadmap and decision support system for all sectors in Qatar (i.e., government, industry, education, society, families, and so on) to follow the pathways toward improving human development and female empowerment for economic diversification. Developing this model and policy framework required a multi-dimensional approach consisting of different stakeholders, intuitions, entities, and society with an integrative and synchronizing strategy to smoothly handle their tight interconnections by exploiting the design and systems thinking methodologies. Figure 2 illustrates the proposed model and policy framework developed on the grounds of a comprehensive literature review of Qatar's current motivators (e.g., QNV 2030 and the UN SDGs) and requirements for building soft power to diversify its economy.

The proposed conceptual model was divided into input, policy proposal and validation, assessment, and output, which are interconnected in a comprehensive system that enables complete, integrated, and effective policy development by synchronizing all entities and sectors (see Figure 3). The input stage consists of two major components: motivators and facilitators. The ultimate motivators are the UN SDGs and QNV 2030. There are many components of these targets, including economic, environmental, social, and human development. To achieve them, Qatar requires economic diversification as a fundamental motivator through industrialization, which should be followed by the development of a knowledge-based economy. The literature review indicates that these outputs can come true by substantially improving human capital and women's empowerment. Thus, these motivators require essential resources, such as human, financial, and physical capital, and demand adoption from a wide range of stakeholders, such as policymakers, academics, laborers, and entrepreneurs. In this regard, the resources and stakeholders constitute the facilitator component, which has a strong interaction with the motivators (see Arrow M1 in Figure 3; hereafter, arrows referred to are in Figure 3).

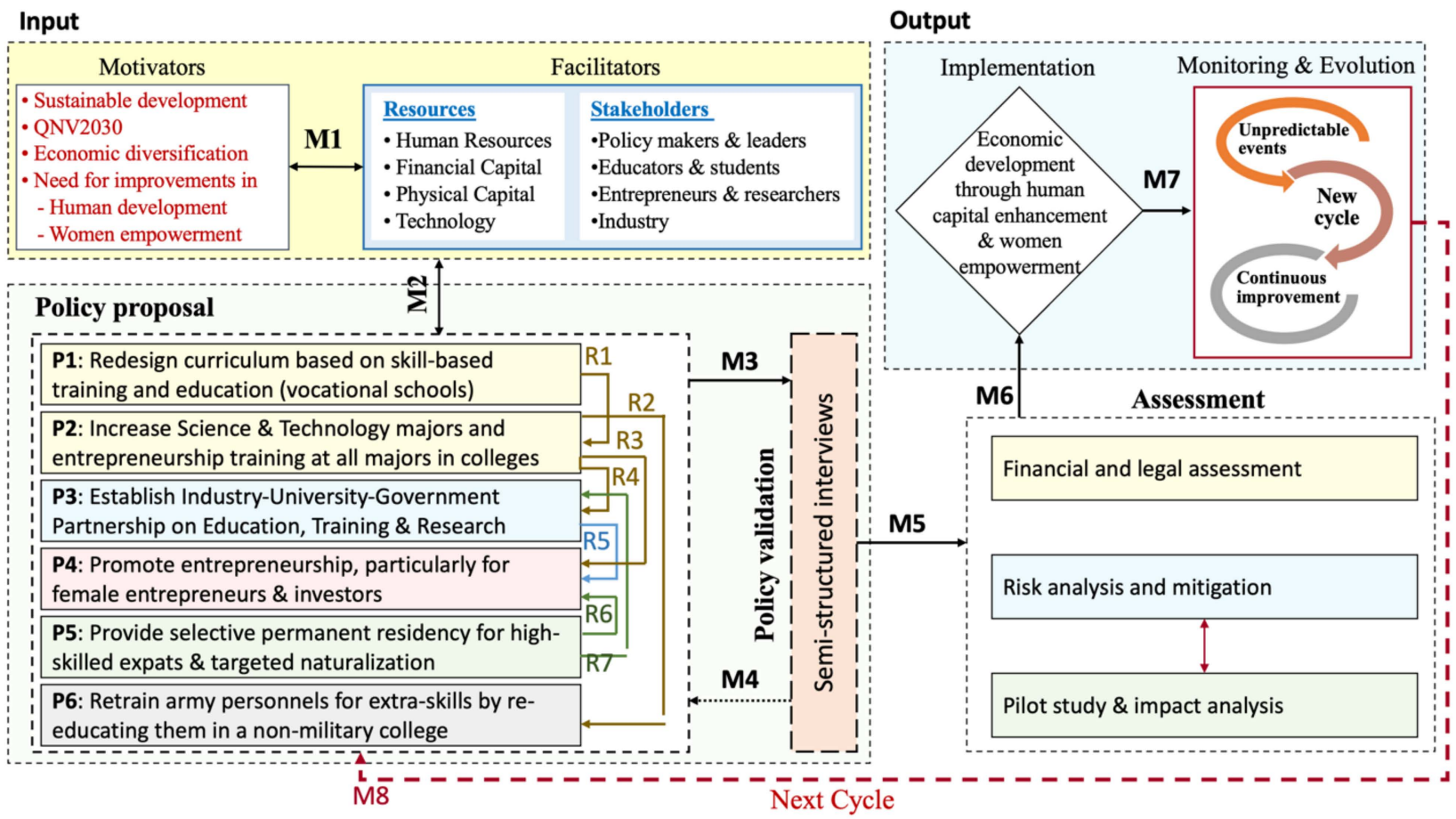

Figure 3. Proposed conceptual model to enhance human capital and female empowerment as a pathway for promoting economic diversification by utilizing the systems thinking approach. 
The following phase of the conceptual model is policy development, which entails two components: policy proposal and policy validation. In the former, we proposed six policies to diversify the economy and progress economic development by enhancing human capital and female empowerment. The policy proposal stage includes a roadmap steered by motivators based on available resources and including all possible stakeholders. Therefore, input and policy proposal (the two initial phases) present robust back-and-forth interactions to deliver optimum pathways for the solution (Arrow M2). Through policy validation, the proposed policies were validated through semi-structured interviews with experts (Arrow M3). If they could not be validated, the process turned back to the policy proposal phase (Arrow M4).

The third building block of the model, assessment, simultaneously involves the evaluation of financial and legal requirements, risk and mitigation strategies, and potential impact analysis along with pilot studies. This phase considers the recommendations and comments stemming from the policy validation stage when performing relevant analyses and evaluations (Arrow M5). After conducting assessments and modifying the proposed policies accordingly, the policies become ready to implement in real life (Arrow M6). The final component in the conceptual framework, output, involves implementing the proposed policies aimed at economic diversification through enhancing human development and female empowerment. The second part of the output component is monitoring and evolution, which involves the continuous implementation of this monitoring and evolution plan to ensure that all system components are working in unison to provide an effective policy framework (Arrow 7M). If there is a need for new policies or modifications to existing policies, then the conceptual model calls this requirement by steering the flow into policy development (Arrow M8).

This conceptual model was developed by employing the systems thinking methodology, and it shows a significantly broad perspective for developing a policy framework for economic development through human capital enhancement and female empowerment. The last two phases of the model, assessment and output, require complex and lengthy procedures and workloads. Thus, we set these stages to represent future work and focused on the policy development phase, which involves policy proposal and validation (explanations for the proposed policies and the interactions between them are provided below).

P1-Redesign curriculum to focus on vocational high schools providing skill-based training and education: The literature shows that Qatar has enacted reforms to make its education system more inclusive, modern, and diverse [47]. However, a significant portion of Qatari youth still does not obtain higher education or the skills required for qualified jobs [79]. Moreover, Qatar lacks vocational high schools in the education system. The absence of such schools significantly limits the transformation of Qatar's unskilled human capital into a promising workforce. Vocational schools can provide skills, training, and high-quality education for individuals that cannot engage in tertiary education, thereby enabling them to participate in the economy [80]. Thus, focusing on vocational schools plays a crucial role in transforming the economy into an industrial economy first and then, ultimately, a knowledge-based economy because such schools can equip students with the necessary occupational and technical skills to meet industry demands and their career desires. Furthermore, they have the potential to serve as a motivator for Qataris to pursue higher education in the same field.

This policy first investigates which vocations are required to be filled by a young workforce for the economic development strategy and provides a quantitative projection to determine the quota for students in vocational high schools for each field. Second, it brings a paradigm shift to the educational system by transforming a certain number of high schools into vocational high schools. An increase in vocational education would also facilitate internships in industry when students are in high school because the curriculum would be designed with vocational school-industry cooperation and periodically updated in line with technological advancements [79]. A trend of skill-based knowledge development 
through a precisely designed curriculum can be incorporated into the $\mathrm{K}-12$ educational structure to enhance skill development.

P2-Increase science and technology majors and entrepreneurship training for all majors in colleges: Although considerable capital has been invested in the Qatari education system, benchmark indicators fail to impress researchers, society, and the economy. Statistically speaking, the students in Qatar remain behind their counterparts worldwide, especially in science and technology (S\&T) [81]. This is an important problem not only for human development but also for economic diversification, playing a crucial role in transitioning through the industrial economy and, ultimately, the knowledge-based economy. Therefore, as a complement to Policy P1 (Arrow R1), there is a requirement for redesigning the higher education system in Qatar by simultaneously providing students with an S\&T-oriented, skills-based education and entrepreneurship training to translate their knowledge into ventures.

This policy requires establishing additional S\&T colleges and equipping them with entrepreneurship education as well as training to encourage students to become entrepreneurs in future S\&T companies. This policy also needs incentives for students to select this kind of field to develop Qatar's economy by providing widespread and generous sponsorships [82]. If incentivization is directed toward building an industrial economy and then a knowledge economy through higher education, Qatar will benefit from these large-scale, extensive, and sustainable effects [83]. Notably, this policy attempts to expand the economic perspective beyond the scope of contemporary market requirements to understand future economic requirements [84].

P3-Establish industry-universities-government partnerships on education, training, and research: There is a pressing need for large-scale collaborations among industry, universities, and government (IUG) to integrate absolute knowledge with practices and applications by including government support. Strong IUG partnerships not only improve human capital but also expand business and industry through the numerous fields that participate in economic diversification. Such collaboration should address the needs, dynamics, and policymaking toward education, training, and research [85]. However, due to a shortage of IUG partnerships in Qatar, there is limited knowledge and skill transformation between universities and industry, which is a major drawback for potential collaboration opportunities aimed at enhancing economic development [50].

This policy should incentivize and encourage industry to collaborate with universities by providing them with various state incentives. Perhaps more importantly, universities should provide the research and knowledge required for industries to solve their specific problems. To this end, universities should recruit high-ranking faculty and academicians to bring their strong knowledge and skills from abroad to Qatar, which requires a strong interaction with Policy 5 (Arrow R7). Furthermore, with the integration of Policy P2 and Policy P4, students will have an opportunity to become entrepreneurs in diversified fields by gaining knowledge and skills from the IUG partnership (Arrow R4 and R5). This partnership has the potential to enable a profound change in cultural context because it brings research-based design to industry and practice-based skills to universities, while both are equipped with entrepreneurship knowledge.

P4-Promote entrepreneurship, particularly for female entrepreneurs and investors: Qatari women's empowerment in social and economic circles has long been restricted due to cultural and regional conventions; however, Qatari females have shown enthusiasm in breaking these obstacles [86]. In recent years, it has been recorded that the number of Qatari females enrolled in higher education is larger than the number of males [87]. However, these women are rarely involved in Qatar's economic activities, especially in entrepreneurial start-ups and as investors [88]. This scarce female involvement is a pressing issue because the number of women graduating from universities is significantly higher than the number of male graduates. Although female involvement is constrained by preexisting bureaucratic requirements, limited funding, and a restrictive legal and cultural 
state of affairs [45], Qatari policymakers are now open to policies for empowering female participation in the economy.

This policy should regulate positive discrimination by favoring women through financing their entrepreneurial activities using various state funds (e.g., innovation and incubation funds). Policies should also provide women with suitable workplaces in technoparks, so that they may become partners in economic development. Additionally, the government should launch a societal campaign to break down cultural and social barriers for female entrepreneurs and investors, while calling on families to encourage female empowerment in economic diversification (and, thus, economic development). Notably, this policy has a strong interaction with Policy P2 in terms of entrepreneurial education and the training of S\&T majors. It also interacts with Policy P3, which relates to the IUG partnership for encouraging females to participate in the economy (Arrows R3 and R5). Moreover, organizational cultures and workspaces should be arranged appropriately to accommodate female-inclusive expansion [89].

P5-Provide selective permanent residency and targeted naturalization for highly skilled expats: Qatar needs to pay close attention to naturalizing highly skilled expatriates because importing global human capital is essential to diversifying the local market with contemporary skills and is an opportunity for the local labor force to learn them [90]. Notably, Qatar has very limited human resources due to its small national population. Therefore, Qatar should strategically explore opportunities so that highly skilled foreign human capital can serve its various interests [91]. Importantly, the quality and merit of the local workforce will significantly improve when it interacts with highly skilled labor from abroad [92]. This localization strategy also results in competition between the local labor force and talented global human resources [93]. However, Qatar shows a limited tendency to provide permanent residency for talented human capital or citizenship for selected permanent residents, despite the country employing a large amount of highly skilled and educated expatriates.

First, this policy should attract new graduates with an S\&T degree equipped with entrepreneurship skills from universities in Qatar by incentivizing successful and brilliant graduates by providing them secure jobs, generous salaries, promising career plans, and then permanent residency. This highlights the close interaction with Policies 2, 3, and 4 (Arrows R6 and R7). Second, this policy should provide fast-tracked visas to attract highly skilled laborers that are in high demand worldwide [94]. However, cultural context must be considered in developing migration policies [95]. Lastly, evaluation systems should assess the impacts of importing well-educated, high-skilled foreign labor and naturalizing them, if they are successfully adopted into society and the economy. As noted in the literature review, this type of policy is essential to ensure that the influx of global human capital is sufficient, while also recognizing sustainability in both long-term economic and cultural contexts.

P6-Retrain army personnel for extra skills by re-educating them in a non-military college: There is a lack of incentives for Qatari men to work in the private sector or establish their own business after graduating from high school or university. This shortcoming is critical for their motivation toward attaining higher education [96]. However, the military and public sectors offer generously high incentives for a low educational requirement. These public sector roles are less competitive in terms of nationality and the requirements and nature of the jobs. The government offers them financial comfort, security, and growth [97]. Working in the public sector is considered prestigious in Qatar's cultural context. Therefore, this fact reduces the need for Qatari males to obtain college degrees. Therefore, instead of pursuing higher education, they prefer working for the military or the police, which is lucrative and secure. Moreover, these jobs offer the irresistible incentive of retirement in one's early 40s. These conventions strongly hinder Qatar's economic transformation to an industrial economy and then a knowledge-based economy [98]. This is because Qatar already has a limited national population. Most males are unwilling to gain new skills 
and talents—particularly in S\&T—or become entrepreneurs, especially after their early retirement.

This policy should incentivize military personnel by increasing their rank in the army and providing free university or college education, preferably as S\&T majors equipped with entrepreneurship (as proposed in Policy 2 (Arrow R2)). This would not only increase human capital but also prepare army personnel for a long and productive period after their retirement. This policy will also lead to the effective use of scarce human resources.

\subsection{Validation and Discussion: Semi-Structured Interview Results}

The semi-structured interviews were conducted to validate the efficacy and feasibility of the proposed policies along with the conceptual model to enhance the human development strategy, with the aim of achieving Qatar's transformation into an industrial and then knowledge-based economy. The conceptual model and policy proposals were presented to each interviewee before asking for their feedback. The interview data were analyzed to capture agreement levels on the proposed policies according to the conceptual model to achieve the study goal, which is to propel the quality of Qatar's human development for economic diversification. Figure 4 demonstrates the segmentation and categorization codes used in this study to facilitate the interpretation of interview results and thereby determine agreement levels for the proposed policies. Based on the six proposed policies, we divided the main findings into high and medium validation levels and then extracted the associated keywords for each policy and agreement level accordingly. Notably, Figure 4 does not illustrate significantly low levels of agreement on Policy 3 and Policy 5. However, Table A1 reports the individual agreement levels of the interviewees, including the lowlevel validations that are also provided in Table A2 and discussed in the following related parts.

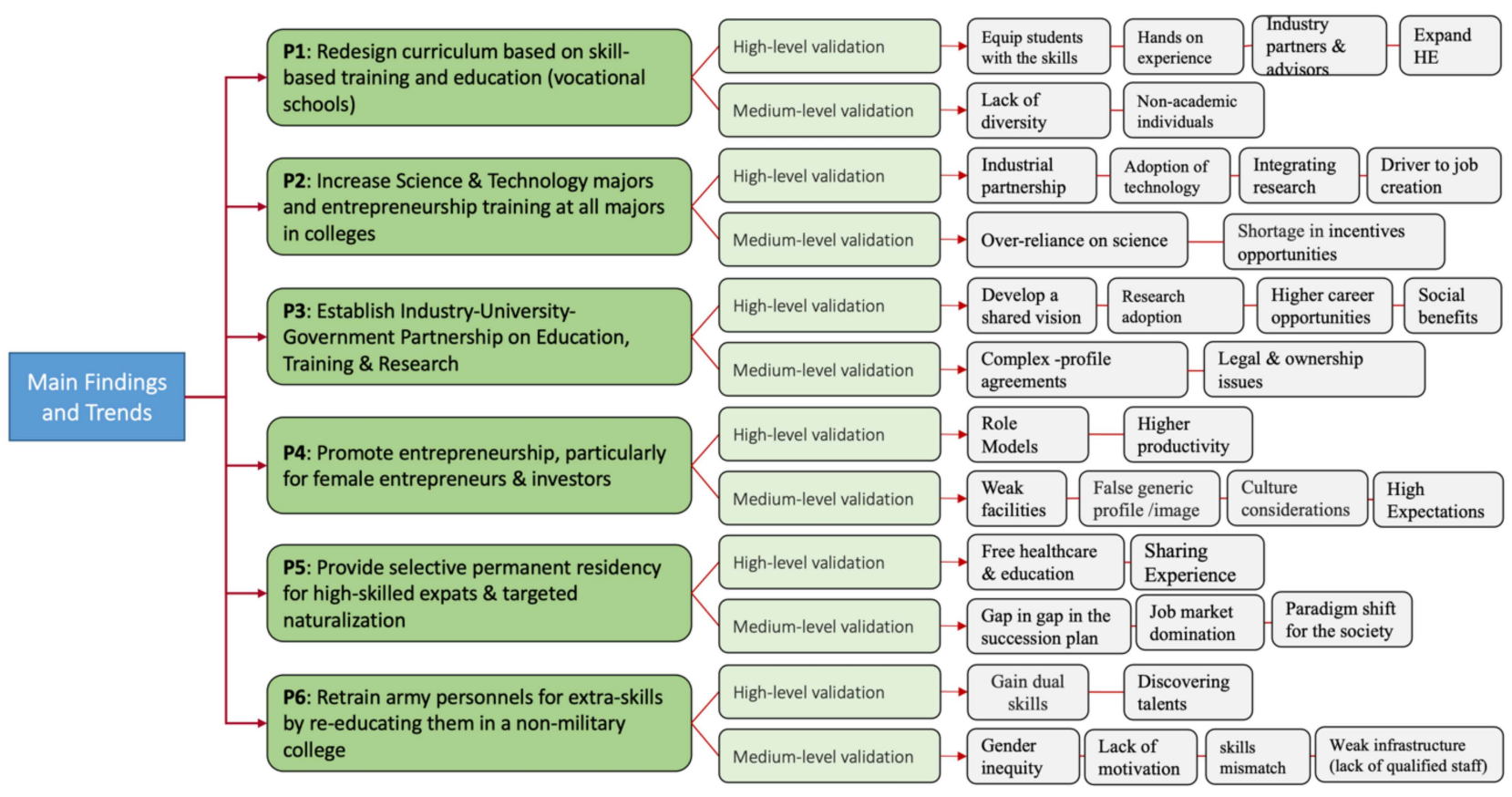

Figure 4. Segmentation and categorization codes for interview results to identify agreement levels for the policies.

Policy 1 (on redesigning the curriculum to focus on vocational high schools providing skill-based training and education) was validated with a high-level agreement level based on the interviewees' responses. The results provide strong evidence supporting the implementation of the policy according to the nine respondents (see Table A1). They agreed on the need to shift and upgrade Qatar's education system to excel in high quality and competitive achievements in skills, talent, and capacity building through vocational 
schools providing useful experience as well as the significant contribution and expansion of higher education. Having vocational high schools as a key factor of designing curriculum at the K-12 level will enable both students and teachers to acquire learning skills that will support them throughout their personal and professional lives, while encouraging them to become innovators and critical thinkers. Additionally, IR5 refers to the fact that vocational high schools serve as a basis for improving earnings in all aspects-both "academic and practical earnings" - which also offers a wider range of career opportunities. In line with this, IR13 refers to the fact that skill-based training leads to life-long learning, by stating "this kind of school offers the ability to upgrade skills based on the required demand". Therefore, vocational high schools and skill-based curriculums are expected to lead to a highly qualified and innovative generation. Furthermore, Policy 1 facilitates the adoption of know-how in many fields by focusing on vocational high schools. These positive impacts confirm the related literature, including studies by Hoeckel [99] and Wonacott [100], even though they contradict on a few opinions [101].

There should be developed life-long learning, job training, and skills improvement strategies linked to industrial demand to implement and efficiently use Policy 1 [102]. Furthermore, the industrial sector must be involved as a co-designer in the curriculum [103]. It is also important to consider teachers, who are the main party involved in Policy 1 . Therefore, improving the conditions of the teaching profession by strengthening leadership skills through training and competency standards is of great importance. Teachers' development and the importance of their professional preparation were confirmed by Al-Thani et al. (2021). Lastly, to achieve the desired outcomes for Policy 1, the use of an ICT strategy is required to provide access to educational technologies for all [104].

Policy 2 is the next step for students who gain an industrial background, hands-on experience, skills, and training in Policy 1 , which encourages higher education in their desired career paths. Policy 2 attained a high validation level from seven participants who agreed with the need to increase S\&T majors and entrepreneurship training at all majors in colleges. The majority of the interviewees believed that this expansion is an investment that provides employees with specialized skills in majors directly related to industrial demand and the knowledge economy. In support of this stance, IR9 reported that "knowledge economy majors and entrepreneurship can be the direct source of-and a strong contributor to- the establishment of new ideas", while IR12 believed that technological and scientific development are channels for economic growth that can satisfy industrial demand and the knowledge economy. Furthermore, the involvement of entrepreneurship in college majors will lead to enhanced economic growth and accelerated efficacy. Such impacts on facilitating the entrepreneurial minds of engineering students were confirmed by Grecu and Denes (2017) [105]. Nevertheless, this contradicts the opinions of some respondents, who believed that negative impacts are possible with an over-reliance on science.

Policies 1 and 2 develop the fundamentals for educating and training students in essential majors that are consistent with industrial demand and entrepreneurial notions. However, these policies alone cannot incorporate these students directly into the economy without a partnership among IUG. Therefore, IUG partnerships become essential to achieve the integrative policy framework of human capital enhancement for Qatar's economic development strategy. In this regard, Policy 3 was validated with a high level of agreement by more than 10 participants. IR3, IR11, and IR13 believed that initiatives should be established to create a collaborative environment between educational institutions, such as schools and universities on the one hand and industry on the other. Such collaborations are expected to create an innovative field of research based on the partnership of key industry actors, while also supporting industry-driven local research, development, and innovation.

This high-level agreement is generally explained by the fact that this collaboration will be critical in directing skills to the identified industrial requirements while simultaneously enhancing relationships with the community. Moreover, this partnership can offer greater access to data and financial support for academic researchers, which is associated with a direct contribution to scientific talent and R\&D. Similar benefits were proven through a 
case study between Kenyatta University and Equity Bank [106]. Some studies question the benefits of this collaboration, especially when it comes to the interaction patterns in different technological fields, as discussed by Meyer-Krahmer and Schmoch (1998) [107]. However, this can be mitigated by developing an early dialog alongside detailed strategies and action plans. For instance, the creation of an intermediary organization specialized in matching academic supply and economic demand under a shared vision would have the potential to mitigate collaboration problems. Second, an exchange of labor between industry sectors and universities as secondment and temporary assignments will lead to strong outcomes and new inputs. This was confirmed by Prigge (2005) in their study on the benefits gained from a university perspective [108]. Additionally, it is important to establish an open digital research and development platform supporting the connection between university research centers and industry.

Policy 4, promoting entrepreneurship, was validated based on the interview resultsparticularly for female entrepreneurs and investors. It has medium-level validation with six high-level and nine medium-level agreement levels. At the high level, IR13 believed such a policy is required but that it should be considered within the context of Qatari culture, where it should involve encouraging women to take initiative from their own homes and engaging them in roles such as becoming entrepreneurs, investors, and mentors. Furthermore, IR 6 stated "initiatives in this direction are of a valuable means to the economy". On the other hand, this policy requires a system development that integrates coaching and financial support for female entrepreneurship, which remains under development in Qatar. The major weakness of Policy 4 is the need to overcome cultural constraints and balance the expectations of females, especially those related to a woman's nature and her fundamental role in the family. Such concerns can still be mitigated, by increasing women's ability to participate in the labor force through affordable childcare, working schemes, and gender equity.

Moreover, Policy 5 can be further supported by creating government offices and women's business centers offering seminars, meetings, web-based information, and networks for female entrepreneurs, which was also confirmed by Ilie et al. (2021) [86]. Furthermore, national and international partnerships can be employed as a development tool to facilitate entrepreneurial endeavors in the economy [109]. Those concerns can be easily mitigated to increase the validation level by paying close attention to developing tailored and progressive policies, programs, and mechanisms to empower the female population, which is already educated well beyond international benchmarks, to contribute broadly to society and the economy.

Policy 5 recommends that the government of Qatar should apply selective and progressive citizenship policies to attract and retain highly skilled expatriates. While this policy was characterized by a medium validation level, on average, there were high-level agreements. IR6 believed that "such a policy encourages highly skilled and highly knowledgeable expats to not only choose to work in Qatar, but also to decide to remain in the country". Additionally, IR9 reported "this policy will encourage expats to be trainers to the Qataris, thereby benefiting the Qatarization policy". On the other hand, few participants have repeatedly stated that the Qatari culture is not yet ready to accept the idea of citizenship for non-nationals. Furthermore, IR1 was concerned about the competition level, stating that "highly skilled residents are already supported via sponsorship" and competition will increase between the residents only, as the nationals' skill level still requires improvement and is not comparable and equivalent to the international level".

This study considered that even if such negative opinions could be reasonably correct, these shortcomings can be mitigated and re-evaluated by developing a clear philosophy that considers the cultural context while managing the migration policy. This point was confirmed by the literature on the effect of immigration on national states, such as the integration of Europe [110]. Furthermore, defining the skills shortages in every sector of the economy and filling relevant industry demands is also needed. Another approach to 
mitigating weakness is the establishment of an evaluation system for monitoring and measuring the success of the applied uses, as discussed by McLaughlan and Salt (2002) [111].

Policy P6, retraining army personnel for extra skills by re-educating them in a nonmilitary college, was validated by seven high-level and eight medium-level agreements from the respondents. Most of the respondents agreed that dual specialization would be beneficial for training in technical, vocational, and leadership for military personnel. This type of flexible training will prepare the individuals that show the greatest potential and are more talented in this way, thereby providing the military with knowledgeable personnel. The average validation level obtained for this policy was medium, and IR7 believed that this training opportunity for extra skills should also be offered to females. On the contrary, IR7, IR13, and IR15 considered this to be a form of gender inequity. Additionally, IR9 believed that there is a possible shortage of job opportunities in other industries, especially after military retirement. However, policies integrating professional military education with talent management and leadership development can be initiated to create technically qualified personnel and sustain high economic growth. Furthermore, Qatar should focus on the development of various skill-based pathways in technical and vocational education that are commensurate with military requirements and other sectors' demands. This was also confirmed by Sánchez (2016) and Zhang et al. (2019) [112,113], who suggested the approach of dual training for military personnel in tech skills and the entrepreneurial approach.

It is worth noting that the proposed human development strategy is not enough alone to accomplish the UN's SDGs and QNV targets, but it will act as a driver and enabler for economic diversification to achieve sustainable development. This study focuses on human development, one of the fundamental pillars of sustainability, and leaves the other main components of the development policies, such as high-tech advancements, environmental protection, energy efficiency, and smart cities, for future studies.

\section{Conclusions}

Different countries design and follow different strategies for their transformations into an industrial economy, followed by a knowledge-based economy. Notably, such strategies are based on their initial and prior conditions in terms of geography, demographics, economic structure, culture, traditions, and history. Qatar's vision and aspiration to transform itself into a sustainable knowledge economy in the coming decades, and gradually move away from its current heavy dependence on oil and gas resources, remains a vital target. Thus, it is critical to understand the current status and recent trajectory of the country's demographics, economic structure, and workforce makeup as well as its geography, culture, and history, to shed light on the achievability of its vision, goals, and strategies for the future. This is particularly true since truly sustainable development can only be realized with the proper preparation of human development and tailored strategies. In this regard, human capital plays a profound role in achieving sustainable development by utilizing the power of well-educated blue and white-collar laborers, academics, politicians, and people from every layer of society and the economy. However, there is no single path for human development; planning, designing, and implementing policies on human capital development and female empowerment requires a country-specific approach. This is because each country presents unique features in terms of its cultural, geographical, regional, economic, social, religious, and historical settings.

Figure 4 summarizes this research on improving human capital and empowering women for sustainable economic development. In the final quarter of the last century, Qatar enjoyed oil and natural gas extraction as well as regional trade that resulted in significant economic growth. At the beginning of this century, Qatar has expanded the natural gas trade globally by developing liquified natural gas (LNG) technology and signing trade agreements with far-reaching countries such as Japan. This LNG expansion has substantially enriched the government and society via the fair distribution of revenue. In line with becoming wealthy, Qatar has been carrying out urban transformation and mega 
infrastructure projects. Thus, its construction sector has also been growing. However, Qatar has become a hydrocarbon-based rentier state due to its rapid growth and development appetite, and it recognizes this fact. Therefore, the Qatari leadership prepared a road map, QNV v.2030, which considers the UN SDGs and emphasizes economic development along with human capital enhancement.

From now on, Qatar has three main options expected for economic growth: continue at the same pace, slow down the increase, or start to decline. The reality of these projections will depend on Qatar's economic development strategy. To continue with the same economic growth acceleration, Qatar should first expand its natural gas technology, devise its derivatives, and invest in extracting hydrogen from the gas. Second, it should diversify its economy through energy-intensive, export-oriented, and high-tech sectors such as advanced manufacturing and materials, biotech, and pharma. Additionally, it has opportunities to exploit the service sector, such as increasing sports (since Qatar is hosting the FIFA World Cup 2022) and health tourism, developing FinTech, and becoming a sustainable financing hub. However, achieving these targets requires an integrative human development strategy (see Figure 5) that also forms this study's motivation. According to various national and international reports, Qatar lacks high-quality education; however, the overall human development index is relatively high. Moreover, this study also focuses on women's empowerment because Qatar was ranked 132 out of 153 countries in facilitating women's economic participation and opportunity [57]. We developed a conceptual model to develop a policy framework by utilizing design and systems thinking. Moreover, we proposed and validated six main policies for economic development strategies involving human capital enhancement and female empowerment. In short, this study is expected to contribute to Qatar's sustainable development vision by attempting economic diversification through a human development strategy.

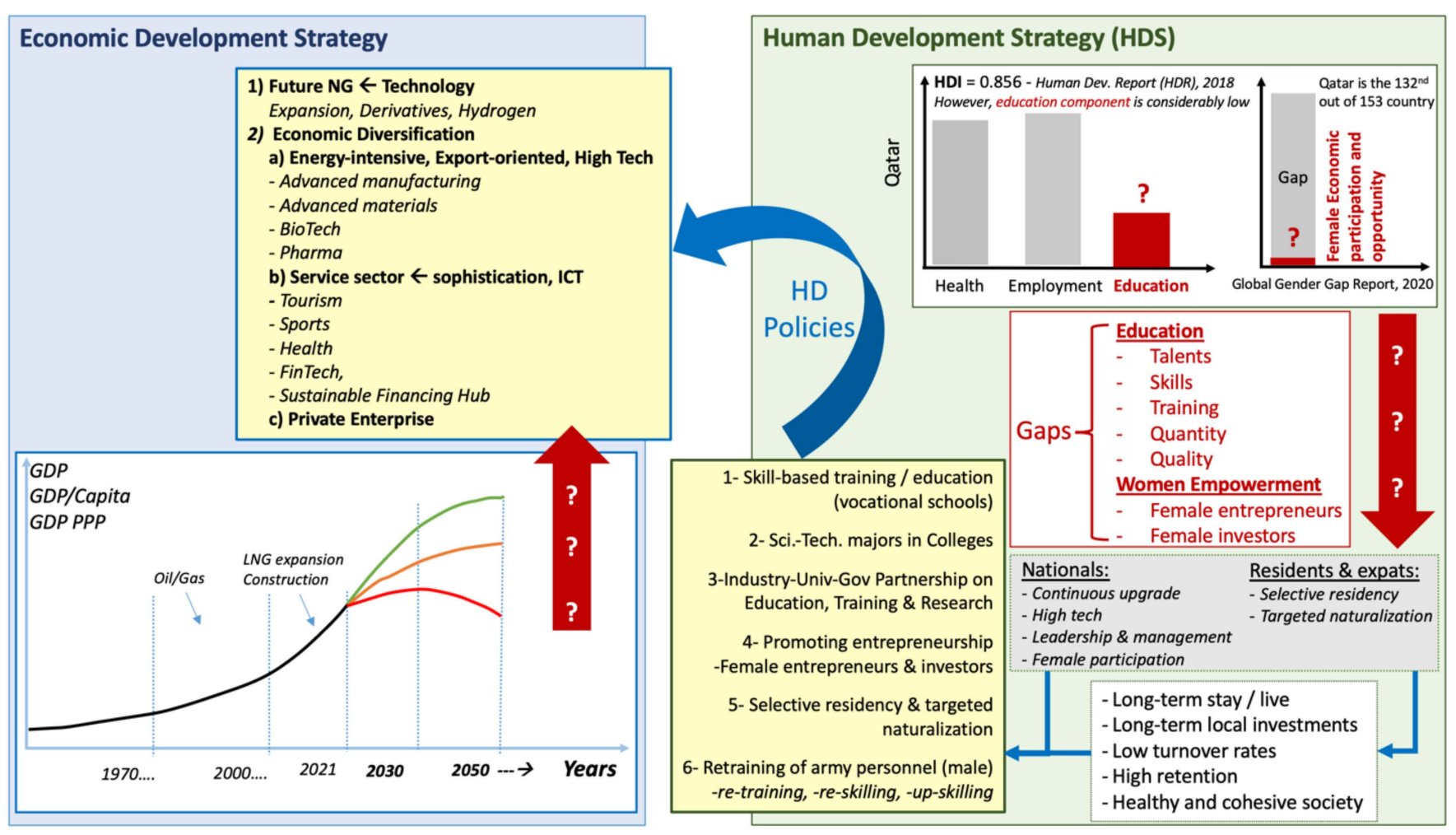

Figure 5. Human capital enhancement and female empowerment in Qatar as critical factors of development. 
However, many of the proposed policies, especially related to vocational high schools, industry-university-government partnership programs, embedding entrepreneurship education in colleges, and women empowerment, are foundational not only to Qatar but also to many countries in the world. In particular, the policy of selective permanent residency and targeted citizenship for highly skilled expatriates can easily be generalized to the other Gulf Cooperation Countries having a low national population, depending on the hydrocarbon-based economy, and presenting low educational output.

The study's main limitation is related to the access to reliable data and information required from the government and different sectors to further justify the proposed framework, which is considerably limited. Therefore, the validation of the proposed model is dependent on the in-depth interviews. However, this approach substantially lessens the effect of the mentioned limitation because the respondents were influential in policymaking.

Thus far, we have developed a policy framework enhancing human capital to contribute to economic sustainability and diversification from a hydrocarbon-based to first an industrial and then a knowledge-based economy. We confined this study in the first three phases of the design thinking approach-discovery, interpretation, and ideation. As future work, we will focus on the remaining two stages-experimentation and evolution. In the experimentation stage, we will conduct financial and legal assessments considering risk mitigation strategies and then design a pilot study to implement the proposed policies in this study. In the meantime, we will determine focal points for each policy and engage them with all the stakeholders. This pilot study will enable us to analyze the shortcomings and potential improvement, and accordingly, adjust the policies with the feedback from the stakeholders. Afterwards, the proposed and improved policy framework will be implemented countrywide. In the last stage, evolution, we will monitor the implemented policies and perform policy impact assessments for both each policy and collaborative output. The system will evolve according to future advances, impacts, and needs, and the new policy requirements will drive the design thinking approach to the first stage in the circle, which is discovery.

Author Contributions: Conceptualization, I.A.; formal analysis, B.H.M.; investigation, B.H.M.; methodology, I.A.; supervision, M.b.S.A.-S. and M.K.; validation, B.H.M.; visualization, I.A.; writingoriginal draft, B.H.M.; writing-review and editing, I.A. and M.K. All authors have read and agreed to the published version of the manuscript.

Funding: The publication of this article was funded by Hamad bin Khalifa University (HBKU).

Institutional Review Board Statement: Not applicable.

Informed Consent Statement: Not applicable.

Data Availability Statement: Not applicable.

Acknowledgments: The authors acknowledge the support provided by Hamad Bin Khalifa University. Many thanks are directed to the anonymous reviewers for their valuable suggestions and critical comments, which tremendously helped in improving this research.

Conflicts of Interest: The authors declare no conflict of interest. 


\section{Appendix A. Agreement Levels of the Interviewees and Their Reasons}

Table A1. Average and individual agreement levels of the interviewees.

\begin{tabular}{|c|c|c|c|c|}
\hline Policy & $\begin{array}{l}\text { Average } \\
\text { Agreement } \\
\text { Level }\end{array}$ & High-Level Validation & $\begin{array}{l}\text { Medium-Level } \\
\text { Validation }\end{array}$ & $\begin{array}{l}\text { Low-Level } \\
\text { Validation }\end{array}$ \\
\hline $\begin{array}{l}\text { P1: Redesign curriculum to focus on } \\
\text { vocational high schools providing } \\
\text { skill-based training and education }\end{array}$ & High & $\begin{array}{l}\text { IR1, IR2, IR3, IR5, IR7, } \\
\text { IR9, IR11, R13, R14 }\end{array}$ & $\begin{array}{l}\text { IR4, IR6, IR8, IR10, } \\
\text { IR12, R15 }\end{array}$ & \\
\hline $\begin{array}{l}\text { P2: Increase science and technology } \\
\text { majors and entrepreneurship } \\
\text { training for all majors in colleges }\end{array}$ & High & $\begin{array}{l}\text { IR1, IR6, IR7, IR9, IR11, } \\
\text { IR12, IR13, IR14, IR15 }\end{array}$ & IR2, R4. IR5, IR8, IR10 & IR3 \\
\hline $\begin{array}{l}\text { P3: Establish } \\
\text { industry-university-government } \\
\text { partnerships on education, training, } \\
\text { and research }\end{array}$ & High & $\begin{array}{l}\text { IR1, R2, IR3, IR5, IR6, } \\
\text { IR7, IR8, IR10, IR11, } \\
\text { IR12, IR13, IR15 }\end{array}$ & IR4, IR9, IR14 & \\
\hline $\begin{array}{l}\text { P4: Promote entrepreneurship, } \\
\text { particularly for female } \\
\text { entrepreneurs and investors }\end{array}$ & Medium & $\begin{array}{l}\text { IR1, IR3, IR5, IR6, IR8, } \\
\text { IR13 }\end{array}$ & $\begin{array}{l}\text { IR2, IR4, IR7, IR9, IR10, } \\
\text { IR11, IR12, IR14, IR15 }\end{array}$ & \\
\hline $\begin{array}{l}\text { P5: Provide selective permanent } \\
\text { residency for highly skilled expats } \\
\text { and targeted naturalization }\end{array}$ & Medium & IR6, IR7, IR9, IR15 & $\begin{array}{l}\text { IR3, IR4, IR8, IR10, } \\
\text { IR11, IR12, IR13, IR14 }\end{array}$ & IR1, IR2, IR5 \\
\hline $\begin{array}{l}\text { P6: Retrain army personnel for extra } \\
\text { skills by re-educating them in a } \\
\text { non-military college }\end{array}$ & Medium & $\begin{array}{l}\mathrm{R} 1, \mathrm{R} 2, \mathrm{R} 4, \mathrm{R} 5, \mathrm{R} 10, \\
\mathrm{R} 11, \mathrm{R} 12\end{array}$ & $\begin{array}{c}\text { R3, R6, R7, R8, R9, R13, } \\
\text { R14, R15 }\end{array}$ & \\
\hline
\end{tabular}

Table A2. Reasons for medium and low agreement levels for the proposed policies raised by respondents.

\begin{tabular}{|c|c|c|c|}
\hline Policy & & Reasons for Medium-Level Validation & Reasons for Low-Level Validation \\
\hline $\begin{array}{l}\text { P1: Redesign curriculum to } \\
\text { focus on vocational high schools } \\
\text { providing skill-based training } \\
\text { and education }\end{array}$ & $\begin{array}{l}2 . \\
3 .\end{array}$ & $\begin{array}{l}\text { Schools do it today as small innovation projects and } \\
\text { annual competitions. It is not implemented in the } \\
\text { curriculum yet. } \\
\text { Lack of R\&D mindset from an early stage; a paradigm } \\
\text { shift is required. } \\
\text { Shortage of the right resources (qualified teaching } \\
\text { staff/technology). It has to be injected into the school } \\
\text { framework along with required curriculum changes. }\end{array}$ & \\
\hline $\begin{array}{l}\text { P2: Increase science and } \\
\text { technology majors and } \\
\text { entrepreneurship training at all } \\
\text { majors in colleges }\end{array}$ & 5. & $\begin{array}{l}\text { It is very challenging since programs must be tailored } \\
\text { to industrial needs, which requires time, effort, and a } \\
\text { new plan. } \\
\text { Nationals have specific preferences toward their future } \\
\text { professions, so a paradigm shift is required before } \\
\text { increasing and initiating majors. }\end{array}$ & $\begin{array}{l}\text { IR3 said: "We do not have the required } \\
\text { capacity building to increase and initiate } \\
\text { science and technology majors" and } \\
\text { "Teachers, students, and authorities } \\
\text { must be co-designers of this process, not } \\
\text { only stakeholders". }\end{array}$ \\
\hline $\begin{array}{l}\text { P3: Establish industry- } \\
\text { university-government } \\
\text { partnership on education, } \\
\text { training, and research }\end{array}$ & $\begin{array}{l}8 . \\
9 .\end{array}$ & $\begin{array}{l}\text { There is a high dependency on international research } \\
\text { and a shortage of local opportunities, which decreases } \\
\text { the significance of industry-university partnerships. } \\
\text { Projects are there, but students lack knowledge on } \\
\text { research meaning, benefits, and resource usage. } \\
\text { IR9 said: "Industry in Qatar is primarily oil } \\
\text { sector-centric; therefore, research outside this area } \\
\text { would bring negligible results if the industry to utilize } \\
\text { the research outcomes is not present in Qatar. Thus, } \\
\text { without diversifying the industrial base, academia will } \\
\text { be guided into areas of required research". }\end{array}$ & \\
\hline
\end{tabular}


Table A2. Cont.

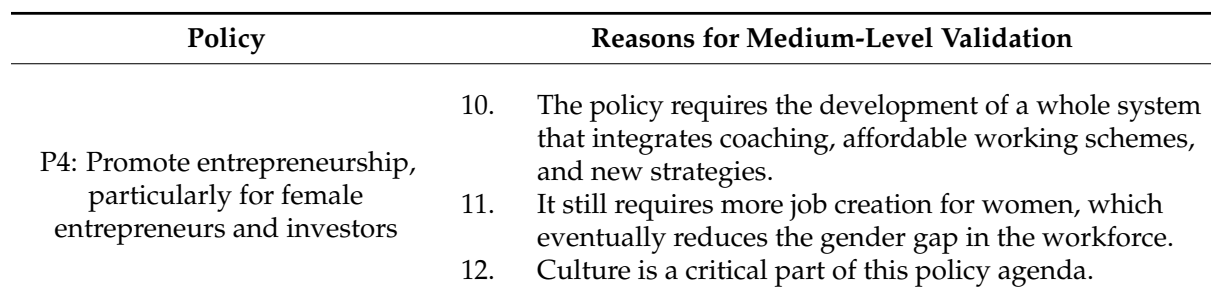

14. IR1 said: "Highly skilled residents are already supported via sponsorship" and "Competition will increase between the residents only, as the nationals skills' level still requires improvement and it is not comparable/equivalent to the international level".

P5: Provide selective permanent residency for highly skilled expats and targeted naturalization
13. IR4 said: "There is a gap in the succession plan. We are learning from their experience and society is not ready yet".
15. IR5 said: "We have a high number of residences. Therefore, we employ scientists and innovators and grant citizenship to this category only. Also, high standards for granting citizenship must exist for precise fields in general science and engineering".
P6: Retrain army personnel for extra skills by re-educating them in a non-military college
16. The training opportunity for extra skills should be offered for females too; otherwise, it is inequity.

17. Although the military forms a small segment of the Qatari population, being natives, they are generally found in leadership roles during and after service.

18. A shortage of jobs in other industries after military retirement.

19. A strategy for human capability and skills development is required.

\section{References}

1. Costantini, V.; Monni, S. Sustainable human development for European countries. J. Hum. Dev. 2005, 6, 329-351. [CrossRef]

2. Schröder, P.; Lemille, A.; Desmond, P. Making the circular economy work for human development. Resour. Conserv. Recycl. 2020, 156, 104686. [CrossRef]

3. Kiker, B.F. Human Capital: In Retrospect; University of South Carolina, Bureau of Business and Economic Research: Columbia, SC, USA, 1968.

4. Blaug, M. The Empirical Status of Human Capital Theory: A Slightly Jaundiced Survey. J. Econ. Lit. 1976, 14, 827-855.

5. Sweetland, S. Human Capital Theory: Foundations of a Field of Inquiry. Rev. Educ. Res. 1996, 66, 341-359. [CrossRef]

6. Winterton, J.; Cafferkey, K. Revisiting human capital theory: Progress and prospects. In Elgar Introduction to Theories of Human Resources and Employment Relations; Edward Elgar Publishing: Cheltenham, uk, 2019.

7. Holden, L.; Biddle, J. The introduction of human capital theory into education policy in the United States. Hist. Polit. Econ. 2017, 49, 537-574. [CrossRef]

8. Simeonova-Ganeva, R. Human Capital in Economic Growth: A Review of Theory and Empirics. Икономическа Мисъл 2010, 7, 131-149.

9. Becker, G.S. Front matter, preface. In Human Capital: A Theoretical and Empirical Analysis with Special Reference to Education, 1st ed.; NBER: New York, NY, USA, 1964; pp. 10-16.

10. Almendarez, L. Human capital theory: Implications for educational development in Belize and the Caribbean. Caribb. Q. 2013, 59, 21-33. [CrossRef]

11. World Bank. Building Knowledge Economies: Advanced Strategies for Development; World Bank: Washington, DC, USA, 2007.

12. Amsden, A.H. Asia's Next Giant: South Korea and Late Industrialization; Oxford University Press: Oxford, UK, 1992.

13. Lee, J.Y. Vocational Education and Training in Korea: Achieving the Enhancement of National Competitiveness; KRIVET: Sejong-si, Korea, 2014; pp. 1-103.

14. Tan, K. Assessment for learning reform in Singapore-Quality, sustainable or threshold? In Assessment Reform in Education; Springer: Berlin/Heidelberg, Germany, 2011; pp. 75-87.

15. Achoui, M.M. Human resource development in Gulf countries: An analysis of the trends and challenges facing Saudi Arabia. Hum. Resour. Dev. Int. 2009, 12, 35-46. [CrossRef] 
16. Barnett, M.L.; Darnall, N.; Husted, B.W. Sustainability strategy in constrained economic times. Long Range Plan. 2015, 48, 63-68. [CrossRef]

17. McSparren, J.; Besada, H.; Saravade, V. Qatar's Global Investment Strategy for Diversification and Security in the Post-Financial Crisis Era'; Centre on Governance, University of Ottawa: Ottawa, ON, Canada, 2017.

18. Ari, I.; Akkas, E.; Asutay, M.; Koç, M. Public and private investment in the hydrocarbon-based rentier economies: A case study for the GCC countries. Resour. Policy 2019, 62, 165-175. [CrossRef]

19. Fetais, S.; Mohsin, A. Assessing Qatar's Readiness and Potential for the Development of a Knowledge Based Economy: An Empirical Analysis of Its Policies, Progress and Perceptions. Ph.D. Thesis, Durham University, Durham, UK, 2013.

20. Meza, A.; Ari, I.; Al-sada, M.S.; Koç, M. Future LNG competition and trade using an agent-based predictive model. Energy Strategy Rev. 2021, 38, 100734. [CrossRef]

21. Khatoon, S.; Zhengliang, X.; Hussain, H. The Mediating Effect of customer satisfaction on the relationship between Electronic banking service quality and customer Purchase intention: Evidence from the Qatar banking sector. SAGE Open 2020, 10, 2158244020935887. [CrossRef]

22. Thompson, E.R. Individual entrepreneurial intent: Construct clarification and development of an internationally reliable metric. Entrep. Theory Pract. 2009, 33, 669-694. [CrossRef]

23. Ministry of Development Planning and Statistics. Realising Qatar National Vision 2030 The Right to Development; Qatar's Fourth National Human Development Report; Al Rayyan Printing Press: Doha, Qatar, 2015; pp. 1-176.

24. Almaamory, A.T.; Al Slik, G. Science and Technology Park as an Urban Element Towards Society Scientific Innovation Evolution. In IOP Conference Series: Materials Science and Engineering, Proceedings of the 1st International Conference on Engineering Science and Technology (ICEST 2020), Samawah, Iraq, 23-24 December 2020; IOP Publishing: Bristol, UK, 2021; Volume 1090, p. 12119.

25. Doha University for Science, Technology to be Established. Available online: https://www.gulf-times.com/story/692955/DohaUniversity-for-Science-Technology-to-be-estab (accessed on 10 December 2021).

26. Ibrahim, I.; Harrigan, F. Qatar's economy: Past, present and future. Qsci. Connect 2012, 2012, 9. [CrossRef]

27. Murray, J.Y.; Zhang-Zhang, Y. Insights on women's labor participation in Gulf Cooperation Council countries. Bus. Horiz. 2018, 61,711-720. [CrossRef]

28. QF. Her Highness Sheikha Moza bint Nasser. Available online: https://www.mozabintnasser.qa/en (accessed on 10 December 2021).

29. Joseph, S. 9 Qatari Women Who Are Inspiring Future Generations to Make an Impact_Emirates Woman. Available online: https:/ / emirateswoman.com/inspiring-women-from-qatar/ (accessed on 10 December 2021).

30. Planning and Statistics Authority in Qatar Woman and Man in the State of Qatar, a Statistical Profile; Planning and Statistics Authority in Qatar: Doha, Qatar, 2018.

31. Abdallah, H. Qatari Women 'Outnumber Men' at Local Universities. Available online: https://www.dohanews.co/qatariwomen-outnumber-men-at-local-universities / (accessed on 10 December 2021).

32. Al-Suwaidi, J.S. Towards a Strategy to Build Administrative Capacity in Light of Human Development for Qatar National Vision 2030. Ph.D. Thesis, University of Bolton, Bolton, UK, 2018.

33. Tsoklinova, M. Mixed economy and economic efficiency: Current issues and challenges. Research Gate. 2015. Available online: https:/ /www.researchgate.net/publication/312409943_MIXED_ECONOMY_AND_ECONOMIC_EFFICIENCY_CURRENT_ ISSUES_AND_CHALLENGES (accessed on 10 December 2021).

34. Estrin, S.; Mickiewicz, T.; Stephan, U. Entrepreneurship, social capital, and institutions: Social and commercial entrepreneurship across nations. Entrep. Theory Pract. 2013, 37, 479-504. [CrossRef]

35. EY Norway. Norwegian Oilfield Services Analysis 2020. 2021. Available online: https://www.ey.com/en_no/oil-gas/norwegianoilfield-services-analysis-2020 (accessed on 10 December 2021).

36. Skarholt, K.; Blix, E.H.; Sandsund, M.; Andersen, T.K. Health promoting leadership practices in four Norwegian industries. Health Promot. Int. 2016, 31, 936-945. [CrossRef]

37. Alsamara, M. The switching impact of financial stability and economic growth in Qatar: Evidence from an oil-rich country. $Q$. Rev. Econ. Financ. 2019, 73, 205-216. [CrossRef]

38. Cardella, G.M.; Hernández-Sánchez, B.R.; Sánchez-García, J.C. Women entrepreneurship: A systematic review to outline the boundaries of scientific literature. Front. Psychol. 2020, 11, 1557. [CrossRef]

39. Kazandjian, R.; Kolovich, M.L.; Kochhar, M.K.; Newiak, M.M. Gender Equality and Economic Diversification; International Monetary Fund: Washington, DC, USA, 2016.

40. Ouedraogo, R.; Marlet, E. Foreign Direct Investment and Women Empowerment: New Evidence on Developing Countries; International Monetary Fund: Washington, DC, USA, 2018.

41. Cuberes, D.; Teignier, M. Gender inequality and economic growth: A critical review. J. Int. Dev. 2014, 26, 260-276. [CrossRef]

42. Fadlelmula, F.; Koc, M. Overall Review of Education System in Qatar; Lambert Academic Publishing: Saarbrücken, Germany, 2016; Volume 20, p. 2016.

43. Parcero, O.J.; Ryan, J.C. Becoming a knowledge economy: The case of Qatar, UAE, and 17 benchmark countries. J. Knowl. Econ. 2017, 8, 1146-1173. [CrossRef]

44. OECD. What makes urban schools different? PISA Focus 2013, 28, 1-4. 
45. Felder, D.; Vuollo, M. Qatari Women in the Workforce; RAND Corporation: Santa Monica, CA, USA, 2008; Available online: https://www.rand.org/pubs/working_papers/WR612.html (accessed on 10 December 2021).

46. Yahia, I.B.; Al-Emadi, M. Exploring the determinants of 2022 FIFA World Cup attendance in Qatar. Int. J. Sport Manag. Mark. 2018, 18, 116-129. [CrossRef]

47. Karkouti, I.M. Qatar's Educational System in the Technology-Driven Era: Long Story Short. Int. J. High. Educ. 2016, 5, 182-189. [CrossRef]

48. Faghih, N.; Sarfaraz, L. Dynamics of innovation in Qatar and its transition to knowledge-based economy: Relative strengths and weaknesses. QSci. Connect 2014, 2014, 23. [CrossRef]

49. Al-Thani, S.B.J.; Abdelmoneim, A.; Cherif, A.; Moukarzel, D.; Daoud, K. Assessing general education learning outcomes at Qatar University. J. Appl. Res. High. Educ. 2016, 8, 159-176. [CrossRef]

50. Pradhananga, R.; Nawaz, W.; Batur, I.; Koç, M. Industry-University-Government Partnership (IUGP)—Trends, Drivers and Policy Recommendations for Qatar. In Proceedings of the ISPIM Innovation Symposium, Melbourne, Australia, 10-13 December 2017; pp. 1-14.

51. Abduljawad, H. Challenges in Cultivating Knowledge in University-Industry-Government Partnerships-Qatar as a Case Study. Res. Gate 2015, 105, 58-77. [CrossRef]

52. Bhanu, M.; Kumar, S. A Study on Global Human Capital \& Its Trends: How to Transform and Design Organiztions into High Performers. Int. J. Hum. Resour. Manag. Res. IJHRMR 2017, 7, 27-42.

53. Pasban, M.; Nojedeh, S.H. A Review of the Role of Human Capital in the Organization. Procedia-Soc. Behav. Sci. 2016, 230, 249-253. [CrossRef]

54. Marimuthu, M.; Arokiasamy, L.; Ismail, M. Human capital development and its impact on firm performance: Evidence from developmental economics. J. Int. Soc. Res. 2009, 2, 8.

55. Susanto, H.; Leu, F.-Y.; Chen, C.K.; Mohiddin, F. Managing Human Capital in Today's Globalization: A Management Information System Perspective; Apple Academic Press: New York, NY, USA, 2019.

56. Mathew, V. Women entrepreneurship in Gulf Region: Challenges and strategies in GCC. Int. J. Asian Bus. Inf. Manag. 2019, 10, 94-108. [CrossRef]

57. Schwab, K.; Crotti, R.; Geiger, T.; Ratcheva, V. Global Gender Gap Report 2020; World Economic Forum: Geneva, Switzerland, 2019.

58. Sohail, M. Women Empowerment and Economic Development-an Exploratory Study in Pakistan. J. Bus. Stud. Q. 2014, 5, 210-221.

59. Khattab, N.; Babar, Z.; Ewers, M.; Shaath, M. Gender and mobility: Qatar's highly skilled female migrants in context. Migr. Dev. 2020, 9, 369-389. [CrossRef]

60. Golkowska, K.U. Arab women in the Gulf and the narrative of change: The case of Qatar. Int. Stud. Interdiscip. Polit. Cult. J. 2014, 16, 51-64. [CrossRef]

61. Al-Thani, W.A.; Ari, I.; Koç, M. Education as a Critical Factor of Sustainability: Case Study in Qatar from the Teachers' Development Perspective. Sustainability 2021, 13, 1525. [CrossRef]

62. Embley, D.W.; Thalheim, B. Handbook of Conceptual Modeling: Theory, Practice, and Research Challenges; Springer: Berlin/Heidelberg, Germany, 2012.

63. Meredith, J. Theory building through conceptual methods. Int. J. Oper. Prod. Manag. 1993, 13, 3-11. [CrossRef]

64. Robinson, S. Conceptual modeling: Definition, purpose and benefits. In Proceedings of the 2015 Winter Simulation Conference (WSC), Huntington Beach, CA, USA, 6-9 December 2015; pp. 2812-2826.

65. Lüdeke-Freund, F. Sustainable entrepreneurship, innovation, and business models: Integrative framework and propositions for future research. Bus. Strateg. Environ. 2020, 29, 665-681. [CrossRef]

66. Eker, S.; Rovenskaya, E.; Obersteiner, M.; Langan, S. Practice and perspectives in the validation of resource management models. Nat. Commun. 2018, 9, 1-10. [CrossRef]

67. Lecours, A. Scientific, professional and experiential validation of the model of preventive behaviours at work: Protocol of a modified Delphi Study. BMJ Open 2020, 10, e035606. [CrossRef] [PubMed]

68. Mohamad, M.M.; Sulaiman, N.L.; Sern, L.C.; Salleh, K.M. Measuring the validity and reliability of research instruments. Procedia-Soc. Behav. Sci. 2015, 204, 164-171. [CrossRef]

69. Rooney, B.J.; Evans, A.N. Methods in Psychological Research; Sage Publications: Thousand Oaks, CA, USA, 2018.

70. Knapik, M. The qualitative research interview: Participants' responsive participation in knowledge making. Int. J. Qual. Methods 2006, 5, 77-93. [CrossRef]

71. Bird, V.; Leamy, M.; Tew, J.; Le Boutillier, C.; Williams, J.; Slade, M. Fit for purpose? Validation of a conceptual framework for personal recovery with current mental health consumers. Aust. N. Z. J. Psychiatry 2014, 48, 644-653. [CrossRef] [PubMed]

72. Martinez-Mesa, J.; González-Chica, D.A.; Duquia, R.P.; Bonamigo, R.R.; Bastos, J.L. Sampling: How to select participants in my research study? An. Bras. Dermatol. 2016, 91, 326-330. [CrossRef]

73. Saunders, B.; Sim, J.; Kingstone, T.; Baker, S.; Waterfield, J.; Bartlam, B.; Burroughs, H.; Jinks, C. Saturation in qualitative research: Exploring its conceptualization and operationalization. Qual. Quant. 2018, 52, 1893-1907. [CrossRef]

74. Miles, M.B.; Huberman, A.M. Qualitative Data Analysis: An Expanded Sourcebook; SAGE Publishing: Thousand Oaks, CA, USA, 1994. 
75. Badrudin, B. The Effectiveness of Study Program Quality Improvement (A Case Study at Islamic Education Management Department, Faculty of Tarbiyah and Teacher Training). In Proceedings of the 6th International Conference on Educational, Management, Administration and Leadership, Bandung, West Java, Indonesia, 28 August 2016; pp. 118-122.

76. Gao, L.X.; Zhang, L.J. Teacher learning in difficult times: Examining foreign language teachers' cognitions about online teaching to tide over COVID-19. Front. Psychol. 2020, 11, 2396. [CrossRef] [PubMed]

77. Albantani, A.M.; Madkur, A. Teaching Arabic in the era of Industrial Revolution 4.0 in Indonesia: Challenges and opportunities. ASEAN J. Commun. Engagem. 2019, 3, 3. [CrossRef]

78. Abd Gani, N.I.; Rathakrishnan, M.; Krishnasamy, H.N. A pilot test for establishing validity and reliability of qualitative interview in the blended learning English proficiency course. J. Crit. Rev. 2020, 7, 140-143. Available online: https:/ / www.semanticscholar.org/paper/A-PILOT-TEST-FOR-ESTABLISHING-VALIDITY-AND-OF-IN-GaniRathakrishnan/692dab005bb47477f3fa733fe8da0bff3e1f599f (accessed on 10 December 2021).

79. Said, Z. 21st Century Skills' Challenges to Postsecondary Tvet Institutions in Qatar. Research Gate. $2021 . \quad$ Available online: https://www.researchgate.net/publication/349297153_21ST_CENTURY_SKILLS\%27_CHALLENGES_TO_ POSTSECONDARY_TVET_INSTITUTIONS_IN_QATAR (accessed on 10 December 2021).

80. Maclean, R.; Fien, J. Introduction and overview: TVET in the Middle East-Issues, concerns and prospects. Int. J. Train. Res. 2017, 15, 197-203. [CrossRef]

81. Hassen, T. Ben Entrepreneurship, ICT and Innovation: State of Qatar Transformation to a Knowledge-Based Economy; Nova Science Publishers, Inc.: Hauppauge, NY, USA, 2019; Available online: https://www.researchgate.net/publication/33581227 0_Entrepreneurship_ICT_and_innovation_state_of_Qatar_transformation_to_a_knowledge-based_economy (accessed on 10 December 2021).

82. Weber, A.S. Education, development and sustainability in Qatar: A case study of economic and knowledge transformation in the Arabian Gulf. In Education for a Knowledge Society in Arabian Gulf Countries; Emerald Group Publishing Limited: Bingley, UK, 2014.

83. Creel, B.; Nite, S.; Almarri, J.E.; Shafik, Z.; Mari, S.; Al-Thani, W.A. Inspiring Interest in STEM Education Among Qatar's Youth. In Proceedings of the 2017 ASEE International Forum, Columbus, OH, USA, 28 June 2017.

84. Sellami, A. A Critical Review of Research on STEM Education in Qatar. Int. J. Hum. Educ. 2021, 20, 19-37. [CrossRef]

85. Moncada-Paternò-Castello, P.; Dosso, M.; Gkotsis, P.; Hervas, F. Industrial Research and Innovation: Evidence for Policy. 2015. Available online: https://www.researchgate.net/publication/308889631_Industrial_Research_and_Innovation_Evidence_for_ Policy (accessed on 10 December 2021).

86. Ilie, C.; Monfort, A.; Fornes, G.; Cardoza, G. Promoting Female Entrepreneurship: The Impact of Gender Gap Beliefs and Perceptions. SAGE Open 2021, 11, 21582440211018468. [CrossRef]

87. Mehrez, A. Investigating critical obstacles to entrepreneurship in emerging economies: A comparative study between males and females in Qatar. Acad. Entrep. J. 2019, 25, 1-15.

88. Al-Ansari, H. Women Are Key to Developing a Knowledge-based Economy in Qatar. Gulf Aff. Spring 2018, 16-18.

89. Los Rios-Carmenado, D.; Ortuño, M.; Rivera, M. Others Private-Public partnership as a tool to promote entrepreneurship for sustainable development: WWP torrearte experience. Sustainability 2016, 8, 199. [CrossRef]

90. Fitjar, R.D.; Timmermans, B. Knowledge bases and relatedness: A study of labour mobility in Norwegian regions. In New Avenues for Regional Innovation Systems-Theoretical Advances, Empirical Cases and Policy Lessons; Springer: Berlin/Heidelberg, Germany, 2018; pp. 149-171.

91. Pozo, L.; Lebrato, J.; Garvi, D.; Jigena, B.; Muñoz Pérez, J.J. Others Naturalization: A new concept developed and carried out in the subject "Environmental Technology" of degree in Industrial Engineering. In Proceedings of the 10th International Technology, Education and Development Conference (INTED), Valencia, Spain, 7-9 March 2016.

92. Jiang, X. Employment effects of trade in intermediate and final goods: An empirical assessment. Int. Labour Rev. 2015, 154, 147-164. [CrossRef]

93. Uprety, D. The impact of international trade on migration by skill levels and gender in developing countries. Int. Migr. 2020, 58, 117-139. [CrossRef]

94. Bauer, T.K.; Kunze, A. The Demand for High-Skilled Workers and Immigration Policy; Forschungsinstitut zur Zukunft der Arbeit Institute for the Study of Labor: Bonn, Germany, 2004.

95. Geddes, A. Migration Policy in an Integrating Europe. 2001. Available online: http://aei.pitt.edu/2086/ (accessed on 10 December 2021).

96. Gremm, J.; Barth, J.; Fietkiewicz, K.J.; Stock, W.G. Transitioning towards a knowledge society. In Qatar as a Case Study; Springer International Publishing AG: Cham, Switzerland, 2018.

97. Alkhulaifi, A. Government Expenditure and Economic Growth in Qatar: A Time Series Analysis. Research Gate. 2012. Available online: https:/ /www.researchgate.net/publication/287865670_Government_expenditure_and_economic_growth_in_Qatar_ A_time_series_analysis (accessed on 10 December 2021).

98. Richer, R.A. Sustainable development in Qatar: Challenges and opportunities. QSci. Connect 2014, 2014, 22. [CrossRef]

99. Hoeckel, K. Costs and Benefits in Vocational Education and Training. Organ. Econ. Coop. Dev. 2008, 8, 1-17.

100. Wonacott, M.E. Benefits of Vocational Education. Myths and Realities, No. 8; ED441179; Columbus ERIC Clearinghouse on Adult Career and Vocational Education, Ohio State University: Columbus, OH, USA, 2000. Available online: https://eric.ed.gov/?id= ED441179 (accessed on 10 December 2021). 
101. Brunello, G.; Rocco, L. The labor market effects of academic and vocational education over the life cycle: Evidence based on a British Cohort. J. Hum. Cap. 2017, 11, 106-166. [CrossRef]

102. Patrick, F. Making the transition to a 'knowledge economy'and 'knowledge society': Exploring the challenges for Saudi Arabia. In Education for a Knowledge Society in Arabian Gulf Countries; Emerald Group Publishing Limited: Bingley, UK, 2014.

103. Graham, G.N.; Sellen, D.B. Light-Scattering Raleigh Linewidth Measurements on G-Actin. Biochem. J. 1971, $125,104-105$. [CrossRef] [PubMed]

104. Stephens, N.M.; Townsend, S.S.M. How can financial incentives improve the success of disadvantaged college students: Insights from the social sciences. In Decision Making for Student Success: Behavioral Insights to Improve College Access and Persistence; Routledge: New York, NY, USA, 2015; pp. 63-78.

105. Grecu, V.; Denes, C. Benefits of entrepreneurship education and training for engineering students. MATEC Web Conf. 2017, 121, 1-7. [CrossRef]

106. Tumuti, D.W.; Wanderi, P.M.; Lang'at-Thoruwa, C. Benefits of university-industry partnerships: The case of Kenyatta University and Equity Bank. Int. J. Bus. Soc. Sci. 2013, 4, 26-33.

107. Meyer-Krahmer, F.; Schmoch, U. Science-based technologies: University-industry interactions in four fields. Res. Policy 1998, 27, 835-851. [CrossRef]

108. Prigge, G.W. University-Industry partnerships: What do they mean to universities? A review of the literature. Ind. High. Educ. 2005, 19, 221-229. [CrossRef]

109. Organisation for Economic Co-Operation and Development (OECD). Promoting Entrepreneurship and Innovative SMEs in a Global Economy. In Proceedings of the 2nd OECD Ministerial Conference on SMEs, Istanbul, Turkey, 3-5 June 2004.

110. Bommes, M.; Geddes, A. Immigration and Welfare: Challenging the Borders of the Welfare State; Routledge: New York, NY, USA, 2000.

111. Mclaughlan, G.; Salt, J. Migration Policies towards Highly Skilled Foreign Workers: Report to the Home Office; Research Development and Statistics Directorate, Home Office: London, UK, 2002.

112. Zhang, Y.; Qin, L.; Wang, X.; Rao, X. Teaching Reform Exploring of Vocational Education Courses with the Guidance of "Military Training and Competition". In Proceedings of the 4th International Conference on Humanities Science, Management and Education Technology (HSMET 2019), Singapore, 21-23 June 2019; Atlantis Press: Singapore; pp. 532-538.

113. Sánchez, R.T. Military Entrepreneurs and the Spanish Contractor State in the Eighteenth Century; Oxford University Press: Oxford, UK, 2016. 